\title{
ENREGISTRER, ORDONNER ET CONTRÔLER: LES DOCUMENTS DIPLOMATIQUES \\ DANS LES REGISTRA SECRETA DE JACQUES II D'ARAGON
}

\author{
STÉPHANE PÉQUIGNOT ${ }^{1}$
}

Date de réception: janvier 2002

Date d'acceptation et version finale: mars 2002

Résumé: L'étude de l'économie interne des Registra secreta de Jacques II montre l'existence d'un «système» spécifique de rassemblement de la documentation diplomatique sous des rubriques legatio. Ce mode de classification n'est cependant pas exclusif, et les registres constituent un véritable lieu d'expérimentation pour l'ordonnancement et le repérage de la documentation enregistrée. L'examen de la tenue des registres conduit alors à celui des fonctions qui leur sont assignées: en facilitant le contrôle des usages de la documentation par les ambassadeurs du roi, ils participent à la chancellerie dune mémoire active de l'administration des affaires diplomatiques.

Mots-clefs: XIII ${ }^{\text {ème }}$-XIV ${ }^{\text {ème }}$ siècles, Couronne d'Aragon, Jacques II, chancellerie, registres, diplomatie, diplomatique.

Abstract: The study of the internal organisation of Jayme IP s Registra secreta shows the existence of a specific «system» for the gathering of diplomatical registered papers in chapters called legatio. However, this method of classification does not exclude other ones and these registers can be considered as an experimental laboratory for the arrangement and the location of registered documents. The composition of the registers and the interventions of the scribes within conduce then to look for the functions they are assigned with: allowing an easier

${ }^{1}$ Université Paris XII-Val de Marne.

Je remercie Maria Teresa Ferrer i Mallol de m'avoir permis de présenter une première version de cet article au Seminari du Departament d'Estudis Medievals du CSIC (Institució Milà i Fontanals) à Barcelone, le 23 octobre 2001. Ma gratitude s'adresse également à Jean-Marie Moeglin, Manuel Sánchez Martínez, Daniel Duran i Duelt, Henri Dolset et Juana Lascham pour leur lecture du texte et leurs remarques. Abréviations utilisées : $\mathrm{ACA}=\mathrm{Arxiu}$ de la Corona d'Aragó (Barcelone), C. = Cancelleria, reg. = registre, $C R=$ Cartes Reials.

«Anuario de Estudios Medievales», 32/1 (2002), pp. 431-479.- ISSN 0066-5061. 
control of the uses of the documentation by the kings ambassadors, the Registra secreta take part, at the chancery, in a living memory of the administration of diplomatical matters.

Key-words: XIIIth-XIVth centuries, Crown of Aragon, Jayme II, chancery, registers, diplomacy, diplomatics.

\section{SOMMAIRE}

I. Genèse et limites d'un système de classification des «documents diplomatiques» dans les Registra secreta. 1. L'enregistrement dans les Registra secreta: acteurs et méthode. 2. L'émergence d'un nouvel ordonnancement de la documentation diplomatique enregistrée: les legationes. 3. Modifications de l'ordonnancement enlegationes au sein des Registra secreta, limites du système.- II. Les Registra secreta: un lieu d'expérimentation pour l'ordonnancement de la documentation diplomatique. 1. Quelques expériences de rassemblement des documents diplomatiques enregistrés. 2. D'un document à l'autre: circuler dans lesRegistra secreta. 3. Les Registra secreta producteurs de récits?- III. LesRegistra secreta: un instrument de contrôle des usages des documents diplomatiques. 1. Contrôler l'élaboration et la remise des documents diplomatiques. 2 . Le contrôle de la documentation diplomatique remise à la chancellerie.

Les registres de la chancellerie royale de la couronne d'Aragon, à Barcelone, constituent un «réservoir de données» ${ }^{2}$ quasiment inépuisable, mais ils font paradoxalement figure de parents pauvres au sein des études médiévales ${ }^{3}$. Ils sont à la fois victimes de la richesse de leur contenu, qui capte l'attention des historiens, et de l'orientation tardive de la diplomatique vers la documentation du bas Moyen Âge, qui requiert une «méthodologie spécifique» (R.-H. Bautier) différente de celle des travaux de cette discipline sur les périodes antérieures ${ }^{4}$. Diplomatistes et historiens de la couronne

${ }^{2}$ Selon l'expression employée au sujet des cartulaires dans O. GuYOTJEANNIN, L. MORELLE et M. PARISSE (dir.), Les Cartulaires Actes de la Table ronde organisée par l'École nationale des chartes et le GDR 121 du CNRS (Paris, 5-7 décembre 1991), Paris: École des Chartes (Mémoires et Documents de l'École des Chartes 39), 1993, p. 8, et développée dans le même recueil par P. GEARY, Entre gestion et gesta, p. 13-26, notamment p. 13.

${ }^{3} \mathrm{~B}$. CANEllas et A. TORRA, Los registros de la cancillería de Alfonso el Magnánimo, Madrid: Archivo de la Corona de Aragón, Ministerio de Educación, Cultura y Deporte, 2000, p. 22 .

${ }^{4} \mathrm{R}$.-H. BAUTIER, Propositions méthodologiques pour la diplomatique du bas Moyen Âge et des débuts de l'époque moderne, dans G. SILAGI (éd.), Landesherrliche Kanzleien im Spätmittelalter. Referate zum VI. Internationalen Kongress für Diplomatik München 1983, Munich (Münchener Beiträge zur Mediävistik und Renaissance-Forschung), 1984, p. 49-59, repris dans R.-H. BAUTIER, Chartes, sceaux et chancelleries Études de diplomatique et de sigillographie médiévale, Paris: École des Chartes (Mémoires et Documents de l'École des Chartes 34), 1990 , tome I, p. 35-45, qui note en particulier: «à mesure qu'on avance dans le temps, le document doit 
d'Aragon ont certes abondamment puisé dans les registres pour décrire le personnel de la chancellerie, analyser les modes d'expédition des actes ou afin d'élaborer des typologies de la documentation ${ }^{5}$, mais la place octroyée aux registres eux-mêmes, en tant que documents à part entière, est demeurée dans leurs travaux singulièrement marginale ${ }^{6}$. Les quelques études qui leur sont spécifiquement consacrées débattent en fait surtout du problème de leur origine et des influences qu'ils ont pu subir ${ }^{7}$, ou bien s'efforcent de reconsti

être de moins en moins considéré en lui-même, mais bien davantage dans le contexte d'autres documents qui permettent de l'interpréter» (p. 40, d'après la réédition de 1990). Sur la diplomatique en général et les orientations actuelles de la discipline en particulier, $\mathrm{cf}$. $\mathrm{O}$. GUYOTJEANNIn, J. PycKe et B.-M. TOCK, Diplomatique médiévale, Turnhout: Brepols (L'Atelier du Médiéviste 2), 1993, en particulier p. 17-28; cf. aussi P. CAMMAROSANO, Italia medievale struttura e geografia delle fonti scritte, Rome: La Nuova Italia Scientifica (Studi Superiori 109), 1996 (quatrième édition), qui note la difficulté actuelle d'une définition de la diplomatique, p. 19.

${ }^{5}$ Sur la chancellerie royale de la couronne d'Aragon, cf. de manière générale J. TRENCHS et A.M. ARAGó, Las cancillerías de la Corona de Aragón y Mallorca desde Jaime I a la muerte de Juan II, Saragosse: Catédra «Zurita» Institución «Fernando el Católico» (CSIC) [Folia Parisiensia I], 1983; pour le règne de Pierre III en particulier, J. TRENCHS, Casa, corte y cancillería de Pedro el Grande (1276-1285), Barcelone: Bulzoni editore (Collana della Sezione di Studi Storici "Alberto Boscolo» Barcellona 3), 1991, p. 19-48, p. 103-150; pour Jacques II, H. FINKE, Acta Aragonensia Quellen zur deutschen, italienischen, französischen, spanischen, zur Kirchen- und Kulturgeschichte aus der diplomatischen Korrespondenz Jaime II. (1291-1327), vol. I, BerlinLeipzig: Dr. Walther Rothschild, 1908, p. XXXIII-CXXII; pour Alphonse III, F.C. CASULA, La cancelleria di Alfonso III il Benigno re d'Aragona (1327-1336), Padoue: CEDAM (Pubblicazioni dell'Istituto di Storia Medioevale e Moderna dell'Università degli Studi di Cagliari 10), 1967, et, pour Pierre IV, F. SEVILlano Colom, Apuntes para el estudio de la cancillería de Pedro IV el Ceremonioso, "Anuario de Historia del Derecho Español», XX (1950), Madrid, p. 137-241; IDEM, De la cancillería de la Corona de Aragón, dans Martínez Ferrando archivero Miscelánea de estudios dedicados a su memoria, Barcelone: Asociación nacional de Bibliotecarios, Archiveros y Arqueólogos, 1968, p. 451-480. Mises au point bibliographiques récentes dans Á. Canellas, Las cancillerías catalano-aragonesas: estado actual de la cuestión, «Boletín de la Sociedad Castellonense de Cultura», LVIII (1982), p. 351-394; F. M. GIMENO BLAY et J. TRENCHS ODENA, La paleografia y la diplomática en España, «Hispania», L/2, 175 (1990), p. 459-472; J. TRENCHS et F. M. GIMENO BLAY, La paleografía y la diplomática en España (siglo XX), Valence: Universitat de València, Departamento de Historia de la Antigüedad y de la Cultura escrita Unidad docente de Paleografía y Diplomática, 1989 (reprint de l'article publié dans A. PETRUCCI et A. PRATESI (éd.), Un secolo di paleografia e diplomatica (1887-1886). Per il centenario dell 'Istituto di Paleografia dell'Università di Roma, Rome: Gela Editrice, 1988), ainsi que la bibliographie complète des travaux de J. TRENCHS, «Estudis Castellonencs», 6 (1994-1995) (Miscel-lània d'Estudis dedicats a la memòria del professor Josep Trenchs i Odena), Castelló: Diputació de Castelló, 1995, p. 39-50.

${ }^{6}$ F.C. CASUla note significativement: «Per lo studio diplomatico della Cancelleria regia interessano solo le Pergamene e le Carte Reali redatte, appunto, dalla Cancelleria. Per la completezza, però, presenteremo anche i Registri, sebbene solo nelle loro caratteristiche esterne, poiché, como vedremo, il contenuto interessa piú lo storico che il diplomatista» (opus cit. (cf. note 5), p. 73); remarque similaire chez F. SEvillano ColOM, opus cit. (cf. note 5), p. 208.

${ }^{7}$ Les historiens ont d'abord émis l'hypothèse d'une influence pontificale à l'origine de la série des registres aragonais, mais cette conception a été remise en cause par A.M. ARAGó et J. TRENCHS, Los registros de cancillería de la Corona de Aragón (Jaime I y Pedro II) y los registros 
tuer les modalités et de fixer le moment précis de l'enregistrement dans la genèse des actes de la chancellerie ${ }^{8}$.

Cependant, comme l'a démontré $O$. Hageneder par son approche novatrice des registres du pape Innocent III, l'étude de l'économie interne des registra mérite elle aussi d'être menée, car elle peut fournir une clef pour comprendre les fonctions qui leur sont assignées, et par conséquent pour mieux discerner les mécanismes d'une chancellerie' ${ }^{9}$. Or, seuls les registres les plus anciens de la chancellerie des rois d'Aragon, ceux de Jacques $\mathrm{I}^{\text {er }}$ le Conquérant et de Pierre III, ont bénéficié d'une analyse détaillée de leur organisation interne, qui demeure à cette période encore très rudimentaire ${ }^{10}$.

pontificios, «Annali della Scuola Speciale per archivisti e bibliotecari dell'Università di Roma», anno XII 1-2 (1972), Turin, p. 26-39, qui soulignent les liens des registres avec les livres de notaires et sont suivis sur ce point par R.I. BURNS (S.J.), Society and Documentation in Crusader Valencia, Princeton, New Jersey: Princeton University Press (Diplomatarium of the crusader Kingdom of Valencia The registered Charters of its Conqueror Jaume I, 1257-1276 I: Introduction), 1985 (édition en catalan avec actualisation bibliographique: Societat $i$ documentació, Valence: Biblioteca d'Estudis i Investigacions Tres i Quatre (Núm. 14) (Diplomatarium I: Introducció Diplomatari del regne croat de València. Els documents registrats de Jaume I el Conqueridor, 1257-1276), 1988, chapitre VIII. Par contre, les influences postérieures subies par les registres font encore l'objet de débat. Á. CANELLAS, Las cancillerías..., opus cit. (cf. note 5), penche ainsi pour une influence du modèle pontifical à travers la voie sicilienne à partir de la conquête de la Sicile en 1283, alors qu'A. KIESEWETTER émet pour sa part l'hypothèse d'une influence des registres angevins (A. KIESEWETTER, La cancellaria Angioina, dans L'État angevin. Pouvoir, culture et société entre XIIr ${ }^{\dot{e} m e}$ et XIV vime siècles (Actes du Colloque international organisé par l'American Academy in Rome, l'École Française de Rome, l'Istituto storico italiano per il Medio Evo, l'U.M.R. Telemme et l'Université de Provence, l'Università degli studi di Napoli «Federico II», Rome-Naples, 7-11 novembre 1995), Rome: École Française de Rome (Collection de l'École Francaise de Rome 245/Istituto Storico per il Medio Evo Nuovi Studi Storici - 45), 1998, p. 361-415, notamment p. 398sq.). Pour l'influence de l'acte pontifical sur les autres chancelleries, cf. P. HERDE et H.JAKOBS (éd.), Papsturkunden und europäisches Urkundenwesen, Studien zu ihren formalen und rechtlichen Kohärenz vom 11. zum 15. Jahrhundert, Cologne, Weimar, Vienne: Böhlau (Archiv für Diplomatik, Schriftgeschichte, Siegel- und Wappenkunde, Beiheft, 7), 1999.

${ }^{8}$ Le problème classique en diplomatique de l'enregistrement à partir de la minute ou à partir de l'original a fait l'objet d'un débat qui demeure ouvert, cf. notamment H. FiNKE, Acta Aragonensia, opus cit. (cf. note 5), p. CXIX-CXXII, et la mise au point de J. TRENCHS et A.M. ARAGÓ, Las cancillerias..., opus cit. (cf. note 5), p. 34-36 et 47-49; pour la transmission de la jussio regis, cf. R. CONDE Y DELGADO DE MOLINA, La transmisión de la jussio regis en la producción documental bajo Jaime II de Aragón: estudio del registro Curie I del Archivo de la Corona de Aragón, dans J. TRENCHS et A.M. ARAGÓ, ibid., p. 83-102.

${ }^{9}$ O. HAGENEDER (dir.), Die Register Innocenz III., Graz-Cologne-Vienne: Verlag Hermann Böhlaus Nachf./Verlag der.Österreichischen Akademie der Wissenschaften (Publikationen des Historischen Instituts beim Österreichischen Kulturinstitut in Rom II. Abteilung Quellen I. Reihe), 7 vol., 1964-1997.

${ }^{10}$ Les registres de Jacques $I^{\text {er }}$ le Conquérant (1213-1276, le premier registre datant de 1257) ont été analysés en dernier lieu par R.I. BURNS (S.J.), opus cit. (cf. note 7), notamment au chapitre VIII. Pour une mise en perspective critique de cet ouvrage, cf. la recension de M.T. FERRER I MALLOL, «Anuario de Estudios Medievales», 21 (1991), p. 695-699. Sur les registres 
Si tous les auteurs s'accordent pour constater ensuite une spécialisation progressive des registres qui comportent pour certains d'entre eux dès 1283 une spécification et se répartissent de manière accrue en séries, leur économie interne et la ventilation des documents entre les séries restent dans l'immense majorité des cas à explorer ${ }^{11}$.

Le règne de Jacques II (1291-1327), qui marque le début de la «chancellerie stable» (J. Trenchs) ${ }^{12}$, constitue dans cette perspective une période cruciale, marquée à la fois par l'accroissement considérable de la documentation enregistrée et par une séparation beaucoup plus nette des registres en des séries spécialisées, comme les Sigilli secreti, les Curiae, les Gratiarum, les Officialium ou bien encore les Registra secreta. L'étude de la tenue, de l'économie interne des quatre registres en papier, aujourd'hui répartis en sept volumes, de cette dernière série présente dès lors un double intérêt. Elle doit d'abord permettre d'examiner comment évolue l'organisation interne des registres d'une même série sur l'ensemble du règne de Jacques II. En second lieu, ainsi que l'avait déjà noté $\mathrm{H}$. Finke dans son étude du Registerwesen de la chancellerie, les Registra secreta, parfois aussi appelés Libri secretorum et postérieurement Legationum, renferment la copie d'un grand nombre de documents concernant les relations avec les puissances étrangères ${ }^{13}$ : lettres de créance, pouvoirs remis aux représentants du roi, sauf-

de Pierre III (1276-1285), cf. J. TRENCHS, Casa.., opus cit. (cf. note 5), p. 134-149, qui développe J. TRENCHS ODENA et R. CONDE Y DELGADO DE MOLINA, Registros y registración bajo Pedro el Grande, XI Congreso di Storia della Corona d'Aragona (Palermo-Trapani-Erice, 25-30 avril 1982) sul tema La società mediterranea all'epoca del Vespro, Palerme: Accademia di Scienze Lettere e Arti, 1984, vol. IV (Comunicazioni), p. 397-407.

${ }^{11}$ Cf. R. CONDE Y DELGADo DE Molina, Analisis de la tipología documental del siglo XIV: fuentes del archivo de la Corona de Aragón, "Cuadernos de Historia Anexos de la revista Hispania», 8 (1977), p. 61. Pour le règne de Jacques II (1291-1327), l'étude fondamentale demeure encore celle d'H. FINKE, Acta Aragonensia, opus cit. (cf. note 5), p. XCV-CXXII [«Das Registerwesen Jaymes II.»], que l'on peut compléter pour la série Officialium par I. BAIGES I JARDI, Els registres Officialium a la Cancelleria de Jaume II: Els oficials reials a Catalunya segons els nomenaments dels registres Officialium (1303-1327), Universitat de Barcelona (Col·lecció de Tesis Doctorals Microfitxades núm. 570), 1990. Eléments de comparaison avec les registres des Archives du Royaume de Valence dans C. LóPEZ RODRíGUEZ, La serie de registros curie de la cancillería regia aragonesa en el Archivo del Reino de Valencia, «Estudis Castellonencs», 7 (1996-1997), p. 491-509.

12 J. TRENCHS et A.M. ARAGÓ, Las cancillerias..., opus cit. (cf. note 5), p. 40-50.

${ }^{13} \mathrm{La}$ série se compose du registre 252 [1292-1300, 238 folios], classé actuellement par erreur parmi les Sigilli secreti, mais qu'H. FINKE a identifié comme le premier des Registra secreta, ainsi que des registres 334-339, nommés postérieurement (au plus tard au XVI ${ }^{\mathrm{eme}}$ siècle) Legationum et qui portent encore cette spécification dans les catalogues. Ces derniers constituaient initialement trois registres, ainsi que le prouve la foliotation d'origine, mais ils se trouvent 
conduits, extraits de la correspondance royale ou bien encore instructions et lettres aux ambassadeurs de Jacques II. Les «documents diplomatiques» ont à plusieurs reprises fait l'objet de typologies fondées sur des critères juridiques et formels ${ }^{14}$, des études de cas ont aussi montré comment on pouvait en user au cours de rencontres diplomatiques ${ }^{15}$, mais une autre hypothèse d'analyse peut être envisagée ici: le rassemblement dans les registres de copies ou de mentions de ces documents contribuerait au contrôle de l'utilisation des originaux emmenés par les ambassadeurs ${ }^{16}$. Il s'agira donc de montrer que les Registra secreta ne se présentent pas seulement comme les témoins d'une étape du processus d'expédition documentaire à la chancellerie aragonaise, mais qu'ils sont le résultat d'efforts de classification de la documentation diplomatique, efforts dont on souhaiterait saisir la logique pour mettre à jour les enjeux qu'ils recouvrent.

actuellement répartis en six volumes [334-335: 1300-1310 (fol. 1-195 et fol. 196-359); 336-337: 1310-1319 (fol. 1-175 et fol. 166-362); 338-339: 1318-1327 (fol. 1-171 et fol. 173-392)], suite à la nouvelle reliure qui leur a été apposée au XIX ${ }^{\text {ème }}$ siècle. Nous adoptons le terme de Registra secreta pour l'ensemble de la série, car c'est le nom qui leur était le plus souvent donné par les contemporains (cf. par exemple le titre Secretum registrum, ACA, C., reg. 336, fol. 5r; le registre 252 est pour sa part nommé Registrum secretorum, ACA, C., reg. 252, fol. 0r). L'idée d'une série homogène apparaît bien dans la note de chancellerie suivante: «Premissa et alia subsequta in dictis pactionibus sunt latius registrata in sequenti registro secreto [...]" (ACA, C., reg. 335, fol. 347v, souligné par nous). Cf. aussi H. FINKE, Acta Aragonensia, opus cit. (cf. note 5), p. CVII-CVIII.

${ }^{14}$ Les «documents diplomatiques», même si les instructions aux ambassadeurs ou les lettres sortent parfois du champ d'études des diplomatistes en raison de l'absence d'une valeur juridique claire qui leur conférerait le statut d'acte écrit, ont depuis longtemps attiré l'attention des historiens, notamment anglo-saxons, cf. D. QUELLER, The Office of the Ambassador in the Middle Ages, Princeton New Jersey: Princeton University Press, 1967, p. 110-148; P. CHAPLAIS, English Medieval Diplomatical Practice (Part I-Documents and Interpretation), 2 vol., Londres: Public Record Office, 1982. Pour la Péninsule ibérique, cf. M.A. OCHOA BRUN, Historia de la diplomacia española, tome III, Madrid: Ministerio de Asuntos Exteriores, 1991, p. 337-354.

${ }^{15} \mathrm{Cf}$. par exemple I. LE BIS, Pratique de la diplomatie. Un dossier d'ambassadeurs français sous Charles VI (1400-1403), "Annuaire-Bulletin de la Société d'Histoire de France» (années 1985-1986), Paris: Libraire C. Klincksieck, 1988, p. 97-215.

${ }^{16}$ G.P. CutTINo, English diplomatical Administration 1259-1339, Oxford: Oxford University Press, 1940, a ainsi démontré comment, à la fin du XIII ${ }^{\text {ème }}$ siècle, s'était développé à la chancellerie royale anglaise l'office du custos processuum, chargé de la conservation et de la communication des documents relatifs aux relations de l'Angleterre avec la France. 


\section{GENÈSE ET LIMITES D'UN SYSTÈME DE CLASSIFICATION \\ DES «DOCUMENTS DIPLOMATIQUES» \\ DANS LES REGISTRA SECRETA}

La documentation diplomatique soulève d'emblée un problème de classification d'ordre fonctionnel pour les chancelleries et les archives, puisqu'il s'agit à la fois de conserver la trace authentifiable de documents expédiés et les originaux reçus. La conservation ou la copie, le classement puis le cas échéant l'utilisation de ces documents s'inscrivent aussi dans le cadre plus global des politiques de maîtrise de l'écrit développées par les pouvoirs royaux et princiers au bas Moyen Âge, que l'étude conjointe du fonctionnement des archives et des usages politiques des dépôts a récemment mises en lumière ${ }^{17}$. Dans les territoires de la couronne d'Aragon, les lettres reçues et les traités sont durant le règne de Jacques II conservés sous forme d'originaux en différents lieux (principalement le palais royal de la capitale comtale, des maisons religieuses comme celles de l'Hôpital de Saint-Jean-deJérusalem et du Temple à Barcelone, des monastères, notamment Sijena et San Juan de la Peña) qui forment l'archivium nostrum des rois d'Aragon jusqu'en 1318, lorsque la «centralisation» (R. Conde) des archives rassemble l'essentiel de cette documentation au palais royal à Barcelone ${ }^{18}$. D'autre part,

\footnotetext{
${ }^{17} \mathrm{Cf}$. les approches variées de P. RÜCK, Die Ordnung des herzoglich-savoyischen Archive unter Amadeus VIII. (1398-1451), "Archivalische Zeitschrift», 67 (1971), p. 11-101 [traduction italienne actualisée: L'ordinamento degli archivi ducali di Savoia sotto Amedeo VIII (1378-1451), Rome (Quaderni della Rassegna degli Archivi di Stato 48), 1977]; M.T. CLANCHY, From Memory to Written Record England 1066-1307, Oxford: B. Blackwell, 1993 (deuxième édition); R. CONDE Y DELGADO DE MOLINA, Los archivos reales o la memoria del poder, XV Congreso de Historia de la Corona de Aragón (Actas), I- El poder real en la corona de Aragón (siglos XIV$X V I)$, I, vol. 2, Jaca, 1995, p. 123-139; O. GUYOTJEANNIN, Les méthodes de travail des archivistes du roi de France (XIII ${ }^{\text {eme }}$-XIV vime siècles), "Archiv für Diplomatik», 42 (1996), p. 295373 , à compléter par O. GUYOTJEANNIN, Super omnes thesauros rerum temporalium: les fonctions du Trésor des Chartes du roi de France (XIV $V^{\text {eme }}-X V^{\text {eme }}$ siècles), dans K. FIANU et DL. GUTH (éd.), Écrit et pouvoir dans les chancelleries médiévales: espace français, espace anglais (Actes du colloque international de Montréal, 7-9 septembre 1995), Louvain-la-Neuve : Fédération Internationale des Instituts d'Études Médiévales (Textes et Études du Moyen Âge 6), 1997 , p. 109-131; pour le XVIII ${ }^{\mathrm{e} m e}$ siècle, D. NAVARRO BONILLA, Los fondos documentales del Archivo del Reino de Aragón: estudio y edición crítica del inventario de José de Yoldi (1749. 1750), Saragosse: Institución "Fernando el Católico» (CSIC), Excma. Diputación de Zaragoza (Fuentes Históricas Aragonesas 34), 2000, p. 9-55.

${ }^{18}$ Sur l'histoire de l'ACA, l'ouvrage fondateur est celui de F. de Bofarull i Sans, Historia del Archivo de la Corona de Aragón, Barcelone: «Pruebas de un libro inédito, anteriores a 1916» [exemplaire unique à l'ACA, cote: LIII/1/112], qui transcrit de nombreux documents sur lesquels se fondent les études postérieures: E. GONZÁLEZ HURTEBISE, Guía histórico-descriptiva del
} 
même si l'on garde parfois des minutes des documents expédiés ${ }^{19}$, la conservation dans la mémoire administrative d'une trace de la documentation diplomatique émise semble surtout un rôle dévolu aux registres, et en particulier aux Registra secreta ${ }^{20}$. En effet, même si certaines instructions aux ambassadeurs rédigées avant 1303 n'ont pas été recopiées ou mentionnées dans les registres (H. Finke) ${ }^{21}$, l'enregistrement des documents diplomatiques avant leur expédition apparaît par la suite comme une pratique très régulière, quoique non systématique. Les nombreuses entrées de documents diplomatiques présentes dans les Registra secreta, dont on ignore le lieu exact où ils étaient gardés ${ }^{22}$, constituent dès lors l'un des aspects d'une politique plus vaste de conservation de la documentation. Dans cette perspective, l'analyse de l'économie interne des registres ne peut être dissociée de celle des pratiques

Archivo de la Corona de Aragón en Barcelona, Madrid, 1920; F. UdiNA MARTORELL, Guía histórica y descriptiva del Archivo de la Corona de Aragón, Madrid: Ministerio de Cultura, 1986. Voir aussi R.I. BURNS, opus cit. (cf. note 7), p. 15-26 et surtout R. CONDE Y DELGADO, Les primeres Ordinacions de l'Arxiu Reial de Barcelona/Las primeras Ordenanzas del Archivo Real de Barcelona 1384, Madrid: Ministerio de Cultura, 1993; IDEM, Archivos y archiveros en la Edad Media peninsular, dans J.J. GENERELO et Á. MORENO LÓPEZ (coord.), Historia de los archivos y de la archivistica en España, Universidad de Valladolid: Secretariado de Publicaciones e Intercambio Científico (Serie: De Archiviis, III), 1998, p. 13-28

${ }^{19}$ Sur les Cartas Reales Diplomaticas (appellation donnée par H. FINKE au siècle dernier), voir en dernier lieu l'introduction de M. SCARLATA, Carte reali diplomatiche di Giacomo II d'Aragona (1291-1327) riguardante l'Italia, Palerme: Documenti per servire alla storia di Sicilia pubblicati a cura della Società Siciliana per la Storia Patria, prima serie- Diplomatica, vol. XXXI, 1993, qui fournit des exemples de minutes.

${ }^{20} \mathrm{Ceci}$ apparaît de manière explicite dans certaines notes de chancellerie qui indiquent que seul le registre conserve une trace du document expédié. La copie d'une lettre remise à Pedro Fernández de Híjar l'autorisant à se rendre en Sicile est ainsi précédée de la note suivante: "Sequens carta fuit tradita nobili Petro Ferdinandi, nulla retenta inde nisi registro [...]" (ACA C., reg. 337, fol. 297v, le document est daté du 27 avril 1316, Tarragone).

${ }^{21}$ R.I. BuRNS (S.J.), opus cit. (cf. note 7), effectue un constat similaire pour le règne de Jacques $\mathrm{I}^{\text {er }}$ : «When circumstances dictated preservation of an original, ever at hand, there was little need for a register-version; this may explain why so many treaties and important public materials are absent from the registers, while so much social history is visible in the more relaxed selection they represent» (p. 52).

${ }^{22}$ De l'examen des ordres de recherche de documents transmis par le roi ou bien des reconnaissances de remise de registres, il ressort que la maison de l'Hôpital de Saint-Jean-deJérusalem à Barcelone a abrité des registres de la chancellerie à certains moments (Cf. ACA, C., CR de Jaume II, caixa $25, \mathrm{n}^{\circ} 3201$, éd. F. de BOFARULL I SANS, opus cit. (cf. note 18), doc. XV p. 40), ce que confirme le Memoriale registrorum des registres de la maison de l'Hôpital, dressé par Mateu Botella en 1306 (ACA, C., Memorial 7/1). Mais ni les documents publiés par F. de BOFARULl I SANS ni l'inventaire de Mateu Botella ne mentionnent spécifiquement les Registra secreta, ce qui relève d'un problème plus général soulevé par R. CONDE: nous ne connaissons pas le lieu de conservation des 300 registres déjà produits en 1318 (R. CONDE Y DELGADO DE MOLINA, Les primeres Ordinacions, opus cit (cf. note 18), p. 14). 
d'enregistrement, elle suppose l'examen préalable des méthodes de travail adoptées par les scribes de la chancellerie.

\section{L'enregistrement dans les Registra secreta: acteurs et méthode}

L'enregistrement, ainsi que l'ont démontré H. Finke et J. Trenchs, occupe une place bien définie dans le processus d'expédition documentaire durant le règne de Jacques II. Il a normalement lieu après que l'ordre, la minute et une première mise au net corrigée ont été effectués, et avant que l'on ne procède à une seconde révision de l'acte, qui prélude à l'apposition éventuelle d'un sceau, à la taxation et à l'envoi du document à l'intéressé23. Néanmoins, le déroulement précis de l'enregistrement, l'identité et le statut des hommes qui l'effectuent posent encore des problèmes d'interprétation pour le règne de Jacques II. Les mentions hors-teneur apposées au bas des transcriptions dans les Registra secreta offrent alors des indications intéressantes. En effet, comme le remarque H. Finke, certaines de ces mentions, par ailleurs absentes des minutes, ne peuvent visiblement pas être apposées sur les actes originaux, car elles contiennent des éléments à ne pas dévoiler aux destinataires ${ }^{24}$. L'enregistrement d'un acte peut donc conduire à l'apposition d'une mention hors-teneur spécifique chargée de rappeler dans le registre les modalités de son élaboration. D'autre part, la transcription de l'acte dans le registre n'est pas nécessairement effectuée par celui qui reçoit le mandat royal et est indiqué dans la mention hors-teneur. Le notaire garde des sceaux Bernat d'Aversó apparaît ainsi dans des mentions hors-teneur d'écritures nettement différenciées et contemporaines ${ }^{25}$. Inversement, on trouve aussi dans les Registra secreta des mentions hors-teneur d'une même écriture, mais qui

${ }^{23}$ H. FinKe, Acta Aragonensia, opus cit. (cf. note 5), p. CXIX-CXXII; A.M. ARAGó et J. TRENCHS, Las cancillerías..., opus cit. (cf. note 5), p. 48-49.

${ }^{24}$ H. FINKE, Acta Aragonensia, opus cit. (cf. note 5), vol. I, p. LXXVIII.

${ }^{25}$ La mention hors-teneur «Bernardus de Aversone, mandato regis, cui fuit lecta per eum et expedita absque signo vicecancellarii de eodem mandato» qui suit une lettre de Jacques II à sa femme Marie de Chypre (ACA, C., reg. 336, fol. 60r (1), 16 décembre 1315, Barcelone) est ainsi d'une écriture différente de celle qui est apposée au folio précédent ("Bernardus de Aversone, mandato regis ») à la suite d'une lettre de Jacques II à Martin Pérez de Oros et Simó Des Llor, datée pourtant du même jour (ibid., fol. 59r-v). 
indiquent différents récepteurs du mandat royal ${ }^{26}$. Il faut par conséquent distinguer le notaire qui reçoit l'ordre du roi et apparait dans la mention horsteneur du scribe chargé d'effectuer la transcription dans le registre, et parfois même le scribe qui copie le document d'un autre scribe qui inscrit à sa suite une mention hors-teneur ${ }^{27}$. L'entrée d'un document dans le registre est donc un travail spécifique, parfois complexe, qui ne se limite pas à la simple copie de la minute par celui qui a reçu le mandat. Cette spécificité de la tâche se traduit-elle alors par une spécialisation de la fonction au sein de la chancellerie?

L'identification des auteurs de l'enregistrement a fait l'objet de remarques contradictoires dans l'historiographie. H. Finke, qui compare l'organisation de la chancellerie de Jacques II à celle qui se trouve dans les Ordenacions (1344) de Pierre le Cérémonieux, considère qu'il n'y a pas encore de séparation nette entre escrivans de manament et escrivans de registres, ces derniers se chargeant sous Pierre IV spécifiquement de l'enregistrement ${ }^{28}$. En revanche, J. Trenchs, qui appuie son analyse sur son étude de la chancellerie de Pierre III et sur les travaux de F.C. Casula pour celle d'Alphonse IV, ne doute pas de l'existence sous Jacques II de scribes de la chancellerie spécialisés dans l'enregistrement, mais avoue ne pas disposer de preuves tangibles ${ }^{29}$. Le problème peut néanmoins être réexaminé à l'aide des notes qui accompagnent parfois dans les registres l'entrée de documents n'émanant pas de la chancellerie de Jacques II. L'annotation «probatum» ou même «probatum cum originali», apposée en général au-dessus de la copie enregistrée avec une écriture distincte, témoigne à plusieurs reprises de la

${ }^{26} \mathrm{Par}$ exemple, la mention hors-teneur «Bernardus de Abbate misit expedi istud ultimum capitulum» (ACA, C., reg. 336, fol. 11v) fait suite à une série d'instructions remises à Bernat de Fonollar qui doit se rendre auprès du pape au début du mois de juin 1310, alors que l'entrée suivante, une lettre de Jacques II au même Bernat de Fonollar, d'une écriture identique, est suivie de la mention hors-teneur «Bernardus de Aversone, mandato regis facto per Petrum Boyl» (ibid., fol. $11 \mathrm{v}(1))$

${ }^{27} \mathrm{C}$ 'est le cas de la copie d'une lettre adressée par Jacques II à son ambassadeur à la curie Vidal de Vilanova, datée du 26 août 1318, à Barcelone. La missive du souverain aragonais est suivie d'une mention hors-teneur d'une main distincte «Bernardus de Aversone, mandato regis, audita per eum et expedita suo mandato, absque vicecancellario» (ACA, C., reg. 338, fol. 15r).

${ }^{28} \mathrm{H}$. FINKE, Acta Aragonensia, opus cit. (cf. note 5), p. LIV-LIX, suivi sur ce point par I. BAIGES I JARDÍ, opus cit. (cf. note 11), p. 118-139. Sur la méthode de H. FINKE, cf. les critiques de F. Sevillano Colom, Apuntes..., opus cit. (cf. note 5).

${ }^{29}$ J. TRENCHS, Las cancillerías, opus cit. (cf. note 5), p. 45; F.C. CASUlA, opus cit. (cf. note 5), p. 33. 
révision de la transcription effectuée au regard de l'original ${ }^{30}$. Or, au-dessous ou en marge de ces copies peuvent aussi se trouver d'autres mentions brèves qui indiquent un nom, parfois accompagné de la précision «de curia $»^{31}$. Cette spécification s'avère très proche de l'un des modes de désignation des scribes spécialisés dans l'enregistrement sous Pierre III, qui sont «curie regis» ${ }^{32}$. D'autre part, les noms mentionnés diffèrent de ceux des notaires qui reçoivent le mandat royal et apparaissent dans les mentions hors-teneur des Registra secreta. L'hypothèse d'une spécialisation de certains scribes qui travaillent aux registres, distincts des escrivans de manament, en sort donc renforcée, même si l'on ne peut guère préciser pour l'heure si Guillem, Jacobus Pa., Jacme Adam et Antoni de Sancta Speria révisent et/ou effectuent la copie de l'ensemble des documents enregistrés ${ }^{33}$.

Dans l'élaboration complexe des Registra secreta, qui demeure encore parsemée de zones d'ombre, le notaire garde des sceaux Bernat d'Aversó joue assurément un rôle central. L'immense majorité des mentions hors-teneur des Registra secreta le désignent comme récepteur direct du mandat du roi ${ }^{34}$, pour lequel il fait figure de «secrétaire personnel ${ }^{35}$. Des notes de chancellerie indiquent que des actes lui ont été transmis avant que l'on ne procède à leur

${ }^{30}$ Cf. ACA, C., reg. 339, fol. 386v; fol. 388v.

${ }^{31}$ La copie d'une bulle de Clément $\mathrm{V}$, déjà surmontée de l'annotation «Probatum cum originali» (ACA, C., reg. 337, fol. 168v) est ainsi accompagnée d'une note marginale: "De cu[ria] Jo. Pa [coupé par le ciseau du relieur]» (ibid., fol. 169r). Autres exemples, mais avec une seule annotation: ACA, C., reg. 338, fol. 21v; fol. 25v.

${ }^{32}$ J. TRENCHS, Casa..., opus cit. (cf. note 5), p. 31.

${ }^{33} \mathrm{O}$. GUYOTJEANNIN note aussi pour le XIII ${ }^{\text {r̀me }}$ siècle la difficulté que l'on éprouve à déterminer le champ d'activité précis des scriptores (O. GUYOTJEANNIN, L'écriture des actes à la chancellerie royale française (XIV $V^{\text {mee }}-X V^{\text {eme }}$ siècles), dans M.-C. HUBERT, E. POULLE, M. H. SMITH (dir.), Le statut du scripteur au Moyen Age (Actes du XII ${ }^{\text {ème }}$ colloque scientifique du Comité international de paléographie latine (Cluny, 17-20 juillet 1998)), Paris: École des chartes (Matériaux pour l'Histoire publiés par l'École des chartes 2), 2000, p. 100).

${ }^{34} \mathrm{Par}$ exemple, pour le registre 338: 429 des 532 mentions hors-teneur (sur 601 documents enregistrés) contiennent des ordres royaux adressés à Bernat d'Aversó, dans leur immense majorité des ordres directs.

${ }^{35}$ Sur Bernat d'Aversó, cf. H. FINKE, Acta Aragonensia, opus cit. (cf. note 5), vol. I, p. XLIX-LIV. Un exemple significatif de son rôle est fourni par une note de chancellerie qui précède la copie d'une lettre du 22 septembre 1312 (Barcelone) adressée à Joan Borgunyó, envoyé en ambassade à la curie: «Preterea dominus rex ordinavit personaliter contenta in quadam cedula scripta per manum Bernardi de Aversone, quam voluit et iussit absque signo cancellarii et tenentis locum suum expediri, et eam tradidit manualiter dicto Bernardo de Aversone includendam in littera supradicta. Cuius cedule tenor sequitur: [...]» (ACA, C., reg. 336, fol. 158v). Pour un exemple d'ordre du roi à Bernat d'Aversó d'expédier un document, ibid., fol. 159r (2). 
enregistrement $^{36}$ et Jacques II lui envoie notamment les instructions aux ambassadeurs formulées en déplacement et scellées du sceau du secret, afin qu'elles puissent figurer dans les registres ${ }^{37}$. La recognition explicite demeure certes un phénomène très rare à l'intérieur des Registra secreta ${ }^{38}$, mais ces derniers paraissent néanmoins par moments constituer véritablement les propres registres de Bernat d'Aversó. Résultat d'un travail spécifique et complexe sans doute contrôlé par le notari tenent-segells de la chancellerie, dans quelle mesure les Registra secreta témoignent-ils alors d'une modification de la répartition des documents diplomatiques entre les registres et d'une transformation de la tenue des registres qui abritent ce type de documentation?

\section{L'émergence d'un nouvel ordonnancement de la documentation diplomatique enregistrée: les legationes}

Durant les règnes des prédécesseurs de Jacques II, Pierre III (12761285) et Alphonse III d'Aragon (1285-1291), bien qu'il n'existe pas de série spécifique, les documents expédiés qui se rapportent aux relations politiques avec des puissances étrangères sont déjà en partie rassemblés dans certains registres de la chancellerie, qui comportent néanmoins d'autres types de

\footnotetext{
${ }^{36}$ Ainsi cette note remarquable qui précède l'enregistrement d'instructions pour une ambassade au Portugal et en Castille en avril 1312, remises par le roi à l'infant Jean d'Aragon, qui les a luimême apportées à Bernat d'Aversó pour enregistrement: «Certum est, quod dictus venerabilis Johanes, frater domini regis, tradidit Bernardo de Aversone in scriptis instructionem, quam dixit sibi datam fuisse per dominum regem super legatione predicta, cuius series sic se habet» (suivent les instructions) (ACA, C., reg. 336, fol. 85v).

${ }^{37}$ «In civitate Ilerde die veneris III idus marcii anno Domini $\mathrm{M}^{\circ} \mathrm{CCC}^{\circ} \mathrm{IIII}^{\circ}$ [5 mars 1315$]$ Petrus Marci, thesaurarius domini regis, ex parte domini regis tradidit Bernardo de Aversone, notario domini regis, quamdam litteram missam dicto domino regi per religiosum virum fratrem Poncium Carbonelli, guardianum fratrum minorum conventus Barchinone, missum pridem per eundem dominum regem ad illustres reges dominos Robertum et Ffredericum. Tradidit etiam eidem quandam sedulam continentem impressionem factam per ipsum dominum regem dicto fratri Poncio sub sigillo secreto nuper in Balagario, ubi erat dictus dominus rex, cuius sedule tenore talis est: [...]» (ACA, C., reg. 337, fol. 350r (1)).

${ }^{38}$ On en trouve une à la suite de la correction d'un pouvoir, opération qui nécessite l'attestation de l'expédition du nouveau document corrigé auprès de la première version du pouvoir: «Et cum dictum procuratorium fuisset expeditum et defficerent ex eo aliqua verba ibi cum dicitur «bonis sedentibus supradictis, hoc recognosco fuit aliud factum et misum, quod registratum est in sequenti carta in fine. (changement d'encre) Et postea fuit recuperatum et laceratum» (ACA, C., reg. 337, fol. 355v, souligné par nous).
} 
documents ${ }^{39}$. Des lettres des rois d'Aragon, des instructions à des ambassadeurs, des pouvoirs et des lettres de créance y sont enregistrés selon un ordre chronologique assez strict, parfois rythmé par des rubriques thématiques -contemporaines ou apposées postérieurement- qui réunissent quelques entrées du registre relatives à une même affaire et permettent ainsi de se repérer plus aisément ${ }^{40}$. Le développement de notes de chancellerie qui peuvent renvoyer à d'autres registres, ainsi qu'à d'autres documents au sein du même registre en indiquant le folio ou l'adresse du destinataire, facilite parfois le repérage des documents enregistrés ${ }^{41}$. Mais l'emploi de rubriques, de notes de chancellerie, c'est-à-dire le recours à des instruments de classification et de repérage des documents diplomatiques au sein des registres, n'est pas encore une pratique régulière ${ }^{42}$.

L'enregistrement des documents concernant les relations diplomatiques de la couronne d'Aragon connaît alors une double mutation après l'accession au trône de Jacques II en 1291, aussi bien pour la répartition des copies entre les registres que pour l'ordonnancement des entrées au sein même des registres. Même si des documents diplomatiques continuent, notamment en début de règne, à être copiés avant leur expédition dans des registres généraux comme les Commune $e^{43}$, le phénomène général de spécialisation des registres de la chancellerie aragonaise touche aussi l'enregistrement des lettres de créance, des instructions, des pouvoirs, des sauf-conduits et des lettres envoyées par le roi d'Aragon à des souverains étrangers ou à ses ambassadeurs. Nombre de ces documents se trouvent désormais rassemblés au sein de

\footnotetext{
${ }^{39} \mathrm{Cf}$. pour Pierre III d'Aragon, ACA, C., reg. 47, fol. 84-fin [1278-1285] que J. TRENCHS, Casa..., opus cit. (cf. note 5), p. 140, qualifie de «registre des relations internationales»; pour Alphonse III d'Aragon (1285-1291), dans l'ordre chronologique: ACA, C., reg. 64, fol. 174-198 [avril 1286-décembre 1287], ACA, C., reg. 77, fol. 1-32 [juin 1288-décembre 1289], appelé au $\mathrm{XVI}^{\text {me }}$ siècle Curiae et Legationum de 1288 a 1289 et ACA, C., reg. 73, fol. 63-105 [décembre 1289-1291], qui porte pour cette partie le titre Super negociis curiae regis Alfonsi. Ces parties de registres correspondent en fait le plus souvent à des cahiers, reliés ensuite à d'autres cahiers pour former les registres.

${ }^{40} \mathrm{Cf}$. pour la copie des accords de Campillo: «Secuntur carte convenientiarum et pactorum initorum inter reges Castelle et Aragonie in Campillo" (ACA, C., reg. 47, fol. 103r). Autres exemples dans ACA, C., reg. 64 , fol. $178 \mathrm{v}$, fol. $181 \mathrm{v}$, etc.

${ }^{41}$ Sur ce point, cf. J. TREnCHS, Casa..., opus cit. (cf. note 5), p. 141-142 et p. 144-145.

${ }^{42}$ En particulier pour l'un des registres d'Alphonse III (ACA, C., reg. 77).

${ }^{43} \mathrm{Cf}$. à ce sujet les remarques de G. BARraClough, A Report on Materials for english History preserved in the Archives of the Crown of Aragon at Barcelona, s.1., 1953, p. 16-17 et H. FinKE, Acta Aragonensia, opus cit. (cf. note 5), p. CI.
} 
registres spécialisés de manière thématique ou géographique ${ }^{44}$, mais ils se concentrent aussi dans trois séries plus générales qui se fixent sous Jacques II, les Curiae, les Sigilli secreti et, surtout, les Registra secreta. Les registres de cette série se distinguent des Sigilli secreti, car, si ceux-ci renferment la copie avant expédition des documents scellés du sceau du secret lorsque le roi est en déplacement, les Registra secreta abritent des documents qui doivent rester secrets ${ }^{45}$, ce critère apparaissant à plusieurs reprises de manière explicite dans des notes de chancellerie qui justifient l'enregistrement ${ }^{46}$. Aucun des Registra secreta ne contient uniquement des copies de documents diplomatiques ${ }^{47}$, mais ces derniers y occupent une place largement prépondérante, ce qui a permis de les considérer comme des registres spécialisés dans les «affaires internationales ${ }^{48}$. Leur appartenance à une série spécialisée qui perdure durant l'ensemble du règne distingue en ce sens les Registra secreta des registres des règnes précédents qui rassemblaient eux aussi des documents diplomatiques.

Toutefois, c'est surtout par leur économie interne que les Registra secreta marquent une rupture avec la période antérieure. Le registre de chancellerie 252 des Archives de la Couronne d'Aragon, le premier de la série $^{49}$, surprend d'emblée par son organisation: après quelques documents de 1297 et des folios blancs, on trouve des entrées de 1294 et 1295 , puis un nouveau retour en arrière est effectué, cette fois-ci jusqu'en 1292, les

${ }^{44} \mathrm{Par}$ exemple les registres 292 (Conventionum et dotum reginarum), 321 (Registrum primi viatici Rome, 1296-1297), 340-341 (Sardiniae) ou bien encore 1521 (Pro negociis Castelle et Aragonum, 1304-1326).

${ }^{45}$ Sur cette distinction importante, cf. H. FINKE, Acta Aragonensia, opus cit. (cf. note 5), p. CXVII-CXVIII.

${ }^{46} \mathrm{En}$ voici quelques exemples: «Hic in hoc presenti registro registratus est de mandato domini regis tenor instrumenti sequentis ad hoc, ut in secreto teneatur» (ACA, C., reg. 337, fol. 191r); «Ideo predicte due littere superius proximo scripte fuerunt hic registrate, quia tangunt factum secretum Tunicii» (ibid., fol. 200v); «[...] Et, quia negocium est secretum, fuerunt in hoc registro registrate» (ACA, C., reg. 339, fol. 228v); «[...]Et, quia negocium hoc agebatur in secretum, fuerunt haec et subsequentes carte in hoc secreto registro registrate» (ibid., fol. 247r) «Haec, que infra registrata sunt, sunt registrata pro secretis de quibus actum est secrete inter dominum regem nostrum et dominum Sancium regem Maioricarum» (ibid., fol. 384r).

${ }^{47} \mathrm{On}$ y trouve en particulier un grand nombre de documents relatifs aux relations du roi avec les infant(e)s.

${ }^{48}$ Cf. A.M. ARAGó et J. TRENChS, Las cancillerías..., opus cit. (cf. note 5), p. 47 qui soulignent les similitudes avec les registres de bulles secrètes de la papauté.

${ }^{49}$ Sur la classification actuelle de ce registre, cf. note 13. 
documents étant ensuite enregistrés de manière globalement chronologique jusqu'en $1300^{50}$. Ces multiples atteintes portées à l'ordre chronologique s'expliquent certainement par une reliure contemporaine erronée des différents cahiers de feuillets qui forment le registre ${ }^{51}$, selon la pratique alors en usage. Néanmoins, au sein de ce désordre apparent, une nouvelle méthode de rassemblement de la documentation diplomatique voit progressivement le jour. Les documents enregistrés sont désormais pour une partie d'entre eux réunis sous des têtes de chapitre (ou rubriques) contemporain(e)s qui portent le titre générique de legatio. C'est une nouveauté, car dans les registres des règnes précédents, le terme legatio apparaissait seulement dans les régestes de documents ou bien dans les notes de chancellerie pour désigner une ambassade $^{52}$. La legatio se hisse dorénavant en tête de chapitre. La première trace en apparaît dès le début du registre 252 où legatio est placé en position de titre, mais sans aucune spécification ${ }^{53}$. À mesure que l'on progresse dans la lecture du registre 252 et des autres Registra secreta, les têtes de chapitre legatio, situées au centre dans la partie haute des feuillets et souvent encadrées par trois traits qui laissent ouverte la partie supérieure du titre, se multiplient et se précisent, pour fournir désormais presque à chaque fois des informations similaires: le nom du ou des chargé(s) de mission, la destination ou le destinataire et, plus rarement, le mobile de la mission. La «Legatio fratris Dominici de Jaccha et Simonis de Lauro in Castella missorum» rassemble

${ }^{50} \mathrm{ACA}, \mathrm{C}$, reg. 252, fol. 1r-3v [1297], fol. 4r-9v [blanc], fol. 10r-23v [1294-1295], fol. 25r238 [1292-1300].

${ }^{51}$ Des erreurs manifestes de reliure conduisent parfois à des incohérences dans les registres. On trouve par exemple la notice suivante: «Item dominus rex providit et mandavit Bernardo de Aversone, quod ipse scribetur per suam litteram predicto fratri Poncio sub forma qua sequitur, qua fuit lecta ipsi domino regi" (ACA, C., reg. 337, fol. 353v), mais la lettre suivante ne correspond pas du tout et il y a un saut de trois années dans le registre. La lettre que le roi a ordonné à Bernat d'Aversó [le notari tenent segells à la chancellerie] de rédiger à l'adresse de frère Pons [Carbonell] se trouve en fait ... 39 folios auparavant (ibid., fol. 314r). Il s'agit d'un problème lié à une reliure d'époque, puisque l'on trouve au folio $313 \mathrm{v}$ une notice d'écriture contemporaine («super isto negocio regum Roberti et Ffrederici habetur infra in III carta et sequentibus»), qui tient compte de la présence «par erreur» de la lettre de Bernat d'Aversó à Pons Carbonell à cet endroit du registre.

${ }^{52} \mathrm{Cf}$. par exemple le régeste «Super legatione quam nobilis Corradus Lancee de mandato domini regis fecit apud regem Granate, facta sibi littera de credencie apud dictum regem Granate. Datum Tirasone V kalendas novembris [1284]» (Tarazona, 28 octobre 1284, ACA, C., reg. 47, fol. 130r-v) et la note de chancellerie: «P. de Deo restituit procuratorium [qui lui avait été donné pour une mission au Maroc] sibi factum per dominum regem super legatione predicta, quod procuratorium fuit ruptum" (ACA, C., reg. 66, fol. 176v, sans date).

${ }^{53} \mathrm{ACA}, \mathrm{C}$, reg. 252 , fol. $1 \mathrm{r}$. 
ainsi la documentation remise au franciscain Domingo de Jaca et au chevalier Simó Dezlor pour la mission qu'ils doivent accomplir en août 1295 en Castille $^{54}$. Cette forme de rubrication, sans jamais être unique ou exclusive, devient de plus en plus régulière dans les Registra secreta et permet à la chancellerie - et aux historiens - de repérer aisément une grande partie des ambassades dépêchées par le roi.

Cependant, la signification exacte du terme legatio que l'on trouve dans les têtes de chapitre des Registra secreta s'avère parfois difficile à déterminer. À première vue, la legatio, selon l'un des sens classiques de ce mot, correspond sans équivoque à l'ambassade, mais ce constat valable de manière générale doit être précisé. Lorsqu'une ambassade itinérante est envoyée auprès de plusieurs souverains étrangers, la documentation qui s'y rapporte peut soit être rassemblée au sein d'une seule legatio ${ }^{55}$, soit être enregistrée sous plusieurs rubriques, avec une legatio pour chaque destinatai$\mathrm{re}^{56}$. D'autre part, les documents relatifs à une ambassade dépêchée auprès d'un destinataire unique sont parfois répartis entre diverses rubriques legatio $^{57}$. La legatio se réfère en ce cas à une mission spécifique confiée à un

${ }^{54}$ Ibid., fol. 19 r.

${ }^{55} \mathrm{Cf}$. la rubrique «Legatio principaliter per dominum Alfonsum et consequenter per dominum regem comissa Simoni de Belloloco, consiliario domini regis ad dominum papam et ad regem Robertum» (ACA, C., reg. 338, fol. 52r, datée Gérone, 23 juillet 1321, d'après le document qui suit fol. $52 \mathrm{r}-\mathrm{v}$ ). La legatio se réfère ici à une mission de Simó de Bel·loc auprès de deux destinataires distincts, le pape Jean XXII et le roi de Naples Robert d'Anjou.

${ }^{56}$ Les documents expédiés en avril 1314 pour le sacristain de Majorque Joan Borgunyó, qui doit se rendre en ambassade auprès de Frédéric III de Sicile et de Robert d'Anjou, sont rassemblés sous deux rubriques: "Legatio comissa per dominum regem nostrum discreto Johanni Burgundi sacriste Maiorice ad illustrem dominum regem Ffredericum» (ACA, C., reg. 337, fol. $211 \mathrm{v}$ ), et «Legatio comissa per dominum regem nostrum discreto Johanni Burgundi sacriste Maiorice ad illustrem dominum regem Robertum» (ibid., fol. 216r). Cf. de manière similaire la mission d'Arnau de Torrelles auprès de Frédéric III de Sicile et de Robert d'Anjou au printemps 1317 (ibid., fol. 310v-311r).

${ }^{57}$ Les documents de l'ambassade confiée en 1315 au noble Bernat Guillem Sa Portella et au sacristain de Majorque Joan Borgunyó auprès du roi de France sont ainsi pour une partie réunis sous la rubrique «Legatio comissa per dominum regem nostrum nobili Bernardo Guillelmi de Portella et venerabili Johanni Burgundi sacriste Maiorice et priori Daroce ad illustrem regem Francie» (ACA, C., reg. 337, fol. 235r), puis, après correction par le roi, sous la rubrique «Legatio comissa per dominum regem nostrum ad regem Ffrancie nobili Bernardo Guillelmi de Portella et Johanni Burgundi sacriste Maiorice et priori Daroce» (ibid., fol. 239v), avant d'être finalement rassemblés sous une troisième rubrique ( It taque supradicta legatio finaliter fuit ordinata et expedita sub forma sequenti» (ibid., fol. 241v)). Or, pour la même ambassade, une autre legatio est confiée aux ambassadeurs, rassemblée sous la rubrique «Sequitur legatio familiaris» (ibid., fol. 247v). De même, la documentation de l'ambassade de Vidal de Vilanova, Dalmau de Pontons et Bernat Despont à la curie en 1313 est enregistrée sous plusieurs rubriques legatio, 
ou à plusieurs représentant(s) du roi, qui n'exclut pas l'existence de missions distinctes à effectuer au cours de la même ambassade. De manière significative, lorsqu'un ambassadeur du roi d'Aragon est déjà arrivé auprès de son destinataire, une nouvelle legatio, c'est-à-dire très clairement une nouvelle mission à accomplir, peut lui être envoyée par le roi ${ }^{58}$. En somme, le sens qui domine pour le terme legatio employé dans les rubriques est bien celui d'ambassade, mais il faut souvent l'entendre au sens d'ambassade ad hoc, de mission spécifique et limitée dans le temps, selon une pratique courante dans les relations diplomatiques de la période ${ }^{59}$.

On trouve alors rassemblée sous ces rubriques legatio la copie ou la mention d'une partie ou de la totalité de la documentation remise aux ambassadeurs du roi à leur départ, c'est-à-dire essentiellement des lettres de créance, des instructions, des pouvoirs, des sauf-conduits et des lettres de Jacques II adressées à des souverains étrangers ${ }^{60}$. Certains documents, en particulier les pouvoirs (procuratoria), sont copiés intégralement sous forme

dispersées dans les registres: «Legatio comissa Vitali de Villanova militi, Dalmacio de Pontonibus vicecancellario et Bernardo de Ponte militi ad dominum papam super bonis templi quondam et quibusdam aliis ut inferius liquide continetur» (ACA, C., reg. 336, fol. 168r) et «Subscripta legatio fuit comissa Vitali de Villanova soli ad dominum papam» (ACA, C., reg. 337, fol. 166r, éd. V. SALAVERT Y ROCA, Cerdeña y la expansión mediterránea de la Corona de Aragón 12971314, Madrid, CSIC, 1956, vol. II, doc. 474, p. 609).

${ }^{58} \mathrm{Guillem}$ Oulomar, juge de la cour du roi, a ainsi été dépêché auprès du pape Jean XXII à la fin du mois de février ou au début du mois de mars 1323 (ACA, C., reg. 338, fol. 125v) au sujet de la conquête de la Sardaigne. Le roi lui envoie ensuite au début du mois d'avril une nouvelle legatio: il doit s'efforcer d'obtenir le cardinalat pour l'évêque de Huesca Gaston de Montcada («Legatio missa Guillelmo Oulomarii predicto ad dominum papam, ut sequitur», ibid., fol. 129v; rubrique datée du 4 avril 1323, Barcelone, d'après la lettre de Jacques II à Guillem Oulomar qui suit, ibid., fol. $129 \mathrm{v}(1))$.

${ }^{59}$ Sur ce point, cf. les remarques générales de D.E. QuELLER, opus cit. (cf. note 14), p. 76, $82,84,88,194$.

${ }^{60}$ Un exemple parmi d'autres nous est fourni avec l'ambassade confiée à Joan Borgunyó et à Lope Sánchez de Luna, envoyés auprès du roi de France et de Charles de Valois sur l'affaire du Val d'Aran. Sous la rubrique «Legatio comissa per dominum regem Aragonie venerabili Johanni Burgundi sacriste Maiorice et canonico valentino, consiliario domini regis, et Lupo Sancii de Luna militi ad regem Ffrancie et ad Karolum fratrem eius super negocio vallis de Aran» (ACA, C., reg. 335 , fol : $235 \mathrm{r}$ ), on trouve rassemblées les copies de lettres de créance auprès de Philippe IV (ibid., fol. 235r (1), Valence, 13 mai 1308) et de Charles de Valois (ibid., fol. 235r (2), Valence, 13 mai 1308), d'un pouvoir pour les deux ambassadeurs d'exiger la restitution du Val d'Aran (ibid., fol. 235v), d'instructions non datées sur les buts de leur ambassade (ibid., fol. $235 \mathrm{v}-237 \mathrm{v}$, éd. C.A. WILlEMSEN, Der Kampf um das Vall d'Aran. Ein Beitrag zur Geschichte der diplomatischen Beziehungen zwischen Aragon und Frankreich um die Wende vom 13. zum 14. Jahrhundert, «Gesammelte Aufsätze zur Kulturgeschichte Spaniens (Spanische Forschungen der Görresgesellschaft Erste Reihe)», VI (1937), doc. 2, p. 197-199), d'autres instructions non datées remises à Lope Sánchez de Luna sur les Templiers (ibid., fol. 237v-238r) et enfin la copie d'une lettre de Charles de Valois à la reine d'Aragon Blanche (ibid., fol. 238r). 
de carta maioris, alors que les sauf-conduits et surtout les lettres de créance sont couramment enregistrés sur le mode du document circulaire. La copie intégrale d'un premier document qui sert de référence réduit dans ce cas l'enregistrement des actes rédigés d'après le même formulaire à de simples mentions qui indiquent l'existence d'un document similaire pour un autre destinataire $^{61}$. Quant aux instructions aux ambassadeurs, qui ne comportent en général ni date ni signes de validation, elles sont copiées intégralement sous les rubriques legatio correspondantes à partir de 1303. Leur présence est souvent annoncée par une sous-tête de chapitre indiquant des capitula ${ }^{62}$, des capitols ou bien encore une informatio (informació) ${ }^{63}$, d'où parfois une véritable prolifération de sous-titres lorsque plusieurs instructions sont rédigées pour une même ambassade ${ }^{64}$. Bien que les documents copiés sous les premières rubriques legatio portent parfois des dates différentes, l'enregistrement s'effectue dans la plupart des cas en une seule fois, comme l'atteste l'emploi d'une même encre par une main unique. L'ordre suivi pour l'enregistrement reprend alors en partie au moins celui de l'usage des documents par les ambassadeurs, puisque les lettres de créance, dont la présentation constitue, après le salut, le premier acte que doit effectuer le

${ }^{61}$ Selon le modèle Similis fuit facta, etc. Sur les différentes façons d'enregistrer les documents dans les registres de la chancellerie, voir la typologie fournie par A.M. ARAGÓ et J. TRENCHS, Las cancillerías, opus cit. (cf. note 5), p. 34-35.

${ }^{62}$ Ces sous-têtes de chapitre sont parfois développées, comme celles qui précèdent la copie des instructions remises à Pere Boïl pour une ambassade auprès des rois. Frédéric III de Sicile et Charles II d'Anjou au printemps 1308: «Capitula tradita dicto Petro de Boyl super legatione ad regem Karolum» (ACA, C., reg. 335, fol. 229v) et "Capitula tradita dicto Petro de Boyl super legatione ad regem Ffredericum» (ibid., fol. 231r).

${ }^{63} \mathrm{La}$ sous-rubrique Informatio précède ainsi les instructions remises à Joan Borgunyó avant son départ à la curie à la fin du mois de janvier 1318 (ACA, C., reg. 337, fol. 313r).

${ }^{64}$ Pour la legatio qu'il doit accomplir à la curie au début du mois de juin 1326 («Legatio comissa ad dominum papam et ad collegium dominorum cardinalium et ad magistrum ordinis hospitalis et alios, ut plenius infra patebit, Berengario de Jorba militi» (ACA, C., reg. 339, fol. $217 \mathrm{r})$ ), Berenguer de Jorba reçoit ainsi plusieurs instructions rassemblées sous le sous-titre général «Informationes tradite Berengario de Jorba nuncio supradicto " (ibid., fol. 217v), chacune de ces instructions étant ensuite précédée d'un titre dans le registre: «Super tributa» (ibid., fol. $217 \mathrm{v}$ ), «Alia informatio» (ibid., fol. 218v, elle-même suivie d'un sous-titre «Super citatione facta domino infanti Petro pro comitatu Impuriarum», ibid., fol. 218v) et enfin «Alia informatio super eodem» (ibid., fol. 219r). 
représentant du roi lorsqu'il rencontre le destinataire de la mission ${ }^{65}$, sont généralement enregistrées avant les autres écrits remis aux ambassadeurs ${ }^{66}$.

Les Registra secreta modifient donc profondément l'ordonnancement de la documentation diplomatique dans les registres de la chancellerie royale de la couronne d'Aragon. Peut-on alors discerner des registres étrangers dont l'organisation leur aurait servi de modèle ? L'influence de chancelleries étrangères sur le développement de celle du roi d'Aragon continue à susciter des débats, qu'il n'est évidemment pas question de trancher ici ${ }^{67}$. Seuls quelques éléments relatifs à l'origine des Registra secreta seront avancés. Bien avant le règne de Jacques II d'Aragon, les registres angevins de Naples comportent déjà une série au titre similaire (Registri secreti), dont l'existence est aujourd'hui attestée par la mention registrata in secretis qui se trouve au dos de nombreux originaux (A. Kiesewetter ${ }^{68}$. Mais la disparition complète de cette série réduit pour l'heure l'influence de la chancellerie angevine

\footnotetext{
${ }^{65}$ Les instructions aux ambassadeurs du roi le spécifient souvent de manière explicite. Par exemple, les instructions remises à Boshom Jiménez, qui doit se rendre auprès des rois de Castille et du Portugal commencent ainsi, après le titre «Informatio tradita dicto Boshom», "Esto es lo que Bosom Ximenez deve dezir al rey de Portugal por la creença a ell comendada, al qual vaya ante que al rey de Castiella.

Primerament le diga como el rey d'Aragón lo envia muyto a saludar.

E presentada a ell la carta de la creença, le diga como el senyor rey, después que le envió sus cartas sobre lo que havia entendido que se tractava matrimonio entre 1 muy noble rey de Castiella e la infanta, filla del dito rey de Portugal, ha avidas otras novas más ciertas que el dito tractamiento es movido [...]" (ACA, C., reg. 339, fol. 236r (3)-v, sans date mais précédé d'un document du 20 août 1327, Barcelone, souligné par nous).

${ }^{66}$ Cette hypothèse permet d'expliquer certaines inversions chronologiques dans l'enregistrement des documents diplomatiques réunis sous une même legatio. Sous la rubrique «Legatio comissa Guillermo de Sancta Columba, scutifero regis, ad regem Maioricarum circa dictum negocium possessionis vallis Aranni» (ACA, C., reg. 336, fol. 105v), une lettre d'accréditation pour Guillem de Santa Coloma auprès de Sanche de Majorque, datée du 5 juin 1313 à Barcelone (ibid., fol. 105v (3), éd. J. REGLÁ CAMPISTOL, Francia la Corona de Aragón y la frontera pirenaica, Madrid, CSIC, 1951, vol. II, app. III, doc. 37, p. 319-320) précède ainsi le pouvoir en latin qui lui a été remis, qui est pour sa part daté du 31 mai 1313, à Barcelone (ibid., fol. 106r (1), éd. J. REGLÁ CAMPISTOL, Francia..., vol. II, app. III, doc. 36, p. 319). Cette inversion chronologique dans l'enregistrement, plutôt que comme une " erreur " du scribe, doit être interprétée comme la conséquence du respect d'un ordre de l'enregistrement de la documentation sous les rubriques legatio, où les lettres de créance précèdent les autres documents.

${ }^{67} \mathrm{Cf}$. note 7. Le problème est rendu d'autant plus complexe qu'une partie essentielle des sources, les registres angevins de Naples et les registres de l'infant Jacques d'Aragon (le futur Jacques II) lieutenant de Sicile, ont disparu. Sur les registres angevins de Naples, cf. R. FILANGIERI et alii (éd.), I registri della cancelleria angioina ricostruiti da Riccardo Filangieri con la collaborazione degli archivisti napoletani, Naples, 1949sq.

${ }^{68}$ Elles apparaissent lors du mouvement de réorganisation de l'enregistrement à la chancellerie du royaume de Naples, mené par Geoffroy de Beaumont à partir de 1268, cf. A. KIESEWETTER, opus cit. (cf. note 7), p. 366-370.
} 
(directement ou par l'intermédiaire de la chancellerie aragonaise de Sicile) sur les Registra secreta de Jacques II à l'état de simple hypothèse ${ }^{69}$. D'autre part, outre une similitude générale de contenu déjà notée par $\mathrm{H}$. Finke et $\mathrm{J}$. Trenchs, les registres contemporains de bulles secrètes de la papauté rassemblent eux aussi les documents sous des rubriques parfois proches de celles des Registra secreta. Le terme legatio est ainsi employé dans quelques têtes de chapitre des registres du pape Jean XXII (1316-1334), en particulier pour réunir la documentation remise aux collecteurs pontificaux ${ }^{70}$. En raison de l'absence d'études comparatives approfondies, il n'est cependant guère possible d'aller au-delà du constat d'un développement contemporain de la rubrication dans les registres des chancelleries pontificale et aragonaise.

Invention de la chancellerie royale aragonaise ou bien adaptation d'un modèle extérieur, les rubriques legatio des Registra secreta permettent de réunir en un même endroit du registre des copies de documents emmenés par les ambassadeurs du roi d'Aragon, alors que l'ordre chronologique qui préside traditionnellement à l'enregistrement n'est initialement que peu perturbé par ce rassemblement thématique de la documentation. Loin de constituer un système figé, l'ordonnancement des entrées sous les rubriques legatio subit toutefois d'importantes évolutions au cours des trente-six années du règne de Jacques II.

${ }^{69} \mathrm{~F}$. BoCK, dans le cadre d'une comparaison avec les registres secrets de Jean XXII, avant la disparition des registres angevins de Robert de Naples (1309-1343), ne trouvait pas parmi eux de registres secrets tenus de manière régulière: «Lediglich Verwaltungsakten füllen auch die unhandlichen Bände der Registerreihe Roberts von Neapel, politische Informationen erhalten wir nur indireckt aus ihnen. Dasselbe gilt für die Register Philipps VI. von Frankreich. Bislang kennen wir aus keiner der genannten Verwaltungen laufend geführte Sekretregister» (F. BOCK, Uber Registrierung von Sekretbriefen Studien zu den Sekretregistern Johanns XXII. "Quellen aus den italienischen Archiven und Bibliotheken», 28 (1937-1938), p. 214)

${ }^{70}$ Des exemples de telles rubriques pour des missions assignées aux collecteurs pontificaux sont présentés par F. BoCK, Studien zur Registrierung der politischen Briefe und der allgemeinen Verwaltungssachen Johanns XXII., "Quellen aus italienischen Archiven und Bibliotheken», 30/31 (1940-1941), p. 137-188. Sur l'enregistrement à la chancellerie pontificale, dont on ne sait toujours pas avec certitude pour la période avignonnaise s'il s'effectuait à partir de l'original ou de la minute, cf. la mise au point bibliographique de T. FrEnZ, Papsturkunden des Mittelalters und der Neuzeit, Stuttgart: Franz Steiner Verlag (Historische Grundwissenschaften in Einzeldarstellungen 2), 2000 (deuxième édition) [traduction italienne de la première édition (1986) sous le titre I documenti pontifici nel Medioevo e nell'età moderna, Vatican: Scuola vaticana di paleografia, diplomatica e archivistica (Littera antiqua, 6), 1989], p. 59-71. 


\section{Modifications de l'ordonnancement en legationes au sein des Registra secreta, limites du système}

À partir de 1302, les têtes de chapitre legatio, qui rassemblaient auparavant seulement des documents remis à l'ambassadeur à son départ, se réfèrent dorénavant souvent à des ensembles documentaires plus vastes, qui comportent en particulier la copie de lettres expédiées postérieurement par Jacques II aux destinataires de l'ambassade, ou aux ambassadeurs eux-mêmes si leur mission se prolonge. Un témoignage remarquable de cette évolution est fourni par l'enregistrement de la documentation relative à l'ambassade solennelle de Bernat Peregrí, Vidal de Vilanova et Guillem de Lacera, partis en janvier 1304 à la curie pour saluer le nouveau pape Clément V et rencontrer le roi de Naples Charles II d'Anjou ${ }^{71}$. La rubrique «Legatio comissa fratri Bernardo Peregrini, priori provinciali ordinis fratrum predicatorum in provincia Aragonie, Vitali de Villanova militi et Guillelmo de Laceria, civi Barchinone» ${ }^{72}$ abrite en son sein, après la copie ou la mention de soixante-deux documents emmenés par les ambassadeurs (lettres de créance ou de recommandation auprès du pape, de personnes influentes à la curie et de marchands, litterae de statu qui informent de l'état de santé de la famille royale aragonaise, demandes de sauf-conduits, pouvoirs, instructions, documents utiles pour les tractations ${ }^{73}$ ) les copies intégrales de dix lettres

${ }^{71}$ Sur les buts de cette mission, cf. de manière générale, V. SALAVERT Y ROCA, opus cit. (cf. note 57), vol. I, p. 240-268; sur les enjeux financiers de l'ambassade, voir aussi J. VINCKE, Staat und Kirche in Katalonien und Aragón während des Spätmittelalters, Münster in Westfalen: Verlag der Aschendorffschen Verlagsbuchhandlung (Spanische Forschungen der Görresgesellschaft zweite Reihe-1. Band), 1931, p. 166-167; sur les méthodes diplomatiques employées, cf. S. PÉQUIGNOT, Interponere partes suas: les bons offices de Jacques II d'Aragon entre les cours de Naples et de Majorque (1301-1304), dans J.-M. MoEGLIN (dir.), L'intercession au Moyen Âge et à l'époque moderne (à paraître).

${ }^{72}$ ACA, C., reg. 334, fol. 181r, éd. V. SAlAVERT Y RoCA, opus cit. (cf. note 57), vol. II, doc. 60 , p. 84.

${ }^{73}$ ACA, C., reg. 334, fol. 181r-184 (1), éd. V. SALAVERT Y RoCA, ibid., vol. II, doc. 60-68 p. 84-95; ibid., fol. 184r (2) [litterae de statu adressée à Marie, femme de Charles II et à Catherine, princesse de Tarente]; ibid., fol. 184r (3)-184v (2), éd. V. SALAVERT Y ROCA, vol. II, doc. 69-70, p. 95-96; ibid., fol. 184v (3) [lettre de Jacques II à un marchand de Pistoia lui demandant de prêter le cas échéant de l'argent aux ambassadeurs]; ibid., fol. 185r (1), éd. V. SALAVERT Y ROCA, vol. II, doc. 71, p. 97; ibid., fol. 185r (2)-(4), éd. V. SALAVERT Y ROCA, vol. II, doc. 76-78, p. 111-113; ibid., fol. 185v-189v, éd. partielle H. FINKE, Acta Aragonensia, opus cit. (cf. note 5), vol. I, doc. 108, p. 157, éd. complète V. SALAVERT Y ROCA, vol. II, doc. 72, p. 98-106; ibid., fol. 190r (1) [régeste indiquant la remise de la copie de huit documents aux ambassadeurs]. Il faut ajouter à ces documents ceux qui sont remis aux ambassadeurs, mais copiés dans d'autres registres: ACA, C., reg. 335, fol. 310, éd. J. VINCKE, Documenta selecta mutuas 
envoyées postérieurement par Jacques II à ses représentants, ainsi que celles de lettres adressées à des princes ou à des cardinaux concernés par l'ambassa$\mathrm{de}^{74}$. L'ultime lettre enregistrée sous cette rubrique legatio tentaculaire est l'ordre de retour envoyé par le roi au dernier de ses ambassadeurs resté à la curie, Vidal de Vilanova, elle est datée du 28 novembre 1304, soit plus de dix mois après le départ de l'ambassade ${ }^{75}$.

La dilatation dans le temps de la documentation réunie sous les rubriques legatio modifie dès lors l'économie interne des Registra secreta. Les folios blancs se multiplient à la suite de la transcription des documents remis aux ambassadeurs, dans l'attente de l'enregistrement de la correspondance qui sera expédiée postérieurement à l'adresse des représentants de Jacques II ou de personnes concernées par l'ambassade ${ }^{76}$. D'autre part, l'ordre de succession chronologique de l'enregistrement, déjà quelque peu chaotique

civitatis arago-cathalaunicae et ecclesiae relationes illustrantia, Barcelone: Biblioteca Balmes (Biblioteca historica de la biblioteca Balmes Serie II, XV), 1936, doc. 100, p. 55-56; ACA, C., reg. 341, fol. 7r, éd. V. SALAVERT Y ROCA, vol. II, doc. 74, p. 108-109; ibid., fol. 6r-v, éd. V'. SALAVERT Y ROCA, vol. II, doc. 75, p. 110-111.

${ }^{74}$ Lettres de Jacques II envoyées aux ambassadeurs ou à l'un d'entre eux: ACA, C., reg. 334, fol. 190r (2)-v (23 janvier 1304, Valence), éd. V. SALAVERT Y ROCA, opus cit. (cf. note 57), vol. II, doc. 80, p. 114; ibid., fol. 190v (1) (Valence, 13 janvier 1304), éd. V. SALAVERT Y ROCA, vol. II, doc. 77, p. 112; ibid., fol. 190v (3) (24 janvier 1304, Valence), éd. V. SALAVERT Y RocA, vol. II, doc. 81, p. 115; ibid., fol. 190v (3) (13 mars 1304, Calatayud), éd. V. SALAVERT Y ROCA, vol. II, doc. 86, p. 119; ibid., fol. $191 \mathrm{r}$ (1) (10 mai 1304, Huesca), éd. V. SALAVERT Y ROCA, vol. II, doc. 89, p. 121; ibid., fol. 191r (2)-v (21 août 1304, Saragosse), éd. V. SALAVERT Y ROCA, vol. III, doc. 103, p. 140-141; ibid., fol. 191v (2)-192r (21 août 1304, Saragosse), éd. V. SALAVERT Y ROCA, vol. II, doc. 104, p. 141-142; ibid., fol. 193r (2) (29 août 1304, Lérida), éd. V. SALAVERT Y ROCA, vol. II, doc. 109, p. 145-146; ibid., fol. 193v (2) (29 août 1304, Lérida), éd. V. SALAVERT Y ROCA, vol. II, doc. 107, p. 144; ibid., fol. 194r (2) (19 septembre 1304, Tortosa), éd. V. SALAVERT Y ROCA, vol. II, doc. 110, p. 146-147. Lettres de Jacques II adressées à des princes étrangers ou à des cardinaux concernés par l'ambassade: ACA, C., reg. 334, fol. 192r (2) (21 août 1304, Saragosse: lettres à Charles II d'Anjou et à Robert, duc de Calabre); ibid., fol. $192 \mathrm{v}-193 \mathrm{r}$ (21 août 1304, Saragosse: lettres adressées à 18 cardinaux). Mais toute la correspondance expédiée relative à l'ambassade n'est pas copiée au même endroit du registre, comme par exemple une lettre adressée à Robert, duc de Calabre (ACA, C., reg. 335 [il s'agit en fait du même registre que le 334, cf. note 13, fol. 310v (23 janvier 1304, Valence), éd. V. SALAVERT Y ROCA, vol. II, doc. 79, p. 113]).

${ }^{75}$ ACA, C., reg. 334, fol. 194v (1), éd. V. SALAVERT Y RoCA, opus cit. (cf. note 57), vol. II, doc. 114 , p. 150.

${ }^{76} \mathrm{Par}$ exemple, dans le registre 338 [ACA, C., reg. 338], la rubrique «Legatio comissa nobili Gueraldo de Rochabertino et Johanni Luppi archidiacono Calataiubii ad dominum papam» concerne les folios $40 \mathrm{r}-44 \mathrm{v}$, puis les folios $45 \mathrm{r}-47 \mathrm{v}$ sont blancs, la «Legatio comissa Bertrando de Gallifa militi ad partes Sicilie» couvre les folios 48r-51r, puis le folio 51v est vierge, avant que la «Legatio principaliter per dominum infantem Alfonsum et consequenter per dominum regem comissa Simoni de Belloloco, consiliario domini regis, ad dominum papam et ad regem Robertum» n'exerce l'office de tête de chapitre pour les folios 52r-58r. 
en raison des erreurs de reliure, est de plus en plus souvent perturbé, puisqu'une nouvelle rubrique legatio peut être ouverte dans le registre, sans que pour autant la précédente soit close ${ }^{77}$. On aboutit par conséquent au sein même de l'organisation en legatio des Registra secreta à un système mixte d'enregistrement de la documentation diplomatique, à la fois thématique par le classement en legatio et en général chronologique à l'intérieur des chapitres $^{78}$, ainsi que d'un début de chapitre à l'autre. Néanmoins, en dépit de leur capacité certaine à ordonner une grande partie de la documentation dans les Registra secreta, les rubriques legatio n'abritent jamais, loin de là, tous les documents enregistrés; elles n'excluent pas d'autres modes généraux de classification complémentaires au sein du registre.

Les Registra secreta contiennent ainsi des entrées qui ne se rapportent à aucune tête de chapitre. Assez nombreuses à l'intérieur du premier registre de la série (1292-1300), dans lequel elles s'intercalent entre les diverses legationes, leur nombre diminue par la suite drastiquement, sans jamais toutefois complètement disparaître ${ }^{79}$. À partir du deuxième registre, cette évolution a pour corollaire l'apparition d'une nouvelle section, dont le titre évoque la diversité et souvent le caractère secret de la documentation qui y est enregistrée: Super parte diversarum registratorum, Littere sparsse, In ista parte registrantur littere sparsse secrete et enfin Super diversis secretis ${ }^{80}$.

${ }^{77} \mathrm{La}$ rubrique «Legatio comissa per dominum nostrum regem ad soldanum Babilonie Berengario de Castro Episcopali militi et Geraldo de Olivaria civi Barchinone de domo domini regis» abrite ainsi des documents expédiés depuis le 6 septembre 1322 jusqu'au 20 août 1327 pour le dernier d'entre eux (ACA, C., reg. 338, fol. 138r-140r); après un folio blanc (fol. 140v), la «Legatio comissa per dominum regem Laurencio Cima judici curie ad regem Tunicii et Bugie» commence par la copie d'une lettre de créance datée du $1^{\text {er }}$ mai 1323 (ibid., fol. 141r), d'où un retour en arrière chronologique dans le registre.

${ }^{78} \mathrm{~L}$ 'ordre chronologique à l'intérieur d'une même rubrique, qui pouvait déjà être perturbé pour l'enregistrement de la documentation remise à l'ambassadeur, peut aussi, quoique plus rarement, être troublé pour les lettres expédiées par le roi aux ambassadeurs. Ainsi une lettre datée du 27 août 1318, à Barcelone et adressée aux ambassadeurs du roi Vidal de Vilanova et Guerau de Rocabertí est-elle enregistrée avant une lettre adressée au seul Vidal de Vilanova et datée du 26 août 1318, à Barcelone (respectivement ACA, C., reg. 338, fol. 12r et ibid., fol. $14 \mathrm{v}(2)-15 \mathrm{r}$ ). Les scribes semblent donc parfois attendre d'avoir plusieurs lettres à copier avant d'effectuer l'enregistrement.

${ }^{79} \mathrm{Cf}$. notamment, ACA, C., reg. 252 , fol. $35 \mathrm{r}-37 \mathrm{v}, 38 \mathrm{v}-41 \mathrm{v}, 44 \mathrm{r}-50 \mathrm{r}, 68 \mathrm{r}-70 \mathrm{v}, 76 \mathrm{v}-81 \mathrm{r}$, $101 \mathrm{r}-\mathrm{v}, 123 \mathrm{v}-124 \mathrm{v}, 129 \mathrm{v}-131 \mathrm{r}, 133 \mathrm{v}-136 \mathrm{r}, 136 \mathrm{v}-144 \mathrm{v}, 149 \mathrm{r}-151 \mathrm{v}, 152 \mathrm{v}-160 \mathrm{v}, 178 \mathrm{r}-217 \mathrm{v}, 223 \mathrm{v}-$ $227 \mathrm{r}$.

${ }^{80}$ Respectivement ACA, C., reg. 335, fol. 296r (qui concerne les folios 296r-299r) et ibid., fol. $299 \mathrm{v}$ (se rapporte aux folios $299 \mathrm{v}-347 \mathrm{r}$, l'ensemble bénéficiant d'une numérotation en chiffres arabes de 1 à 51); ACA, C., reg. 337, fol. $317 \mathrm{v}$ (se réfère aux folios $317 \mathrm{v}-362 \mathrm{r}$ ); ACA, C., reg. 339, fol. 369r (se réfère aux folios 369r-383v). Dans le registre 252 (1292-1300), une section 
Dans ces parties des Registra secreta qui possèdent parfois une numérotation propre et qui couvrent ordinairement toute la période embrassée par le registre originel $^{81}$, les rubriques legatio demeurent une denrée rare et l'enregistrement s'effectue essentiellement selon l'ordre chronologique. Les réponses à des ambassades ou à des lettres envoyées depuis l'étranger côtoient ici des lettres adressées à des ambassadeurs de Jacques II, à des nobles de la couronne d'Aragon ou bien encore des copies de lettres envoyées par le roi aux infants, en particulier dans le dernier registre de la série ${ }^{82}$. La documentation bariolée de ces miscellaneae secretae se compose en fait pour une bonne part d'actes qui doivent demeurer secrets, mais que leur spécificité empêche de s'adapter à l'ordonnancement des têtes de chapitre legatio.

Cette section accueille néanmoins aussi des documents qui pourraient en théorie tout aussi bien se trouver sous une rubrique legatio de la première partie d'un Registrum secretum ${ }^{83}$. Il arrive en effet parfois que, faute de place, l'enregistrement ne puisse plus être effectué là où règne l'ordonnancement en legatio; le scribe copie alors le document dans la deuxième partie du registre, celle des «secrets variés». Ceci se produit notamment si, après l'enregistrement des documents remis à l'ambassadeur, l'espace laissé vierge pour la correspondance à expédier postérieurement s'avère insuffisant ${ }^{84}$. De même, lorsqu'il n'est plus possible de consigner une legatio dans la première partie du Registrum secretum, elle peut être enregistrée intégralement dans la

similaire, mais sans tête de chapitre, se trouve aux folios $178 \mathrm{r}-217 \mathrm{v}$.

${ }^{81}$ Cf. ACA, C., reg. 335, fol. 296r sq. (numération en chiffres arabes). Les sections Super parte diversarum registratorum et Littere sparsse du registre 335 couvrent la période octobre 1301-avril 1310, c'est-à-dire le champ embrassé par le registre originel aujourd'hui divisé en deux volumes (cf. note 13); la section In ista parte registrantur littere sparsse secrete du registre 337 contient des documents datés de février 1311 à avril 1319 (les volumes 336-337 vont de 1310 à 1319), enfin la section Super diversis secretis du registre 339 abrite des entrées qui vont de mars 1319 à octobre 1323 (les volumes 338-339 vont de 1318 à 1327).

${ }^{82}$ ACA, C., reg. 339, fol. 369r-383v.

${ }^{83}$ H. FinKe, Acta Aragonensia, opus cit. (cf. note 5), vol. I, p. CXI-CXII, parle d'un «lien lâche» entre les deux parties des Registra secreta, mais sans définir précisément la nature de ce lien.

${ }^{84}$ Dans le registre 337 , les premiers documents relatifs à l'ambassade du maestre racional Pere Boill envoyé auprès du pape en février 1318 se trouvent ainsi enregistrés sous la rubrique Legatio comissa Petro Boyl ad dominum papam à partir du folio $283 \mathrm{r}$. Cependant, une fois au folio $316 \mathrm{v}$ du registre (tous les documents enregistrés entre-temps ne se réfèrent pas à cette unique ambassade), où il consigne encore la copie de lettres de créances et de recommandation pour l'ambassadeur, le scribe est en fait arrivé au seuil de la partie intitulée In ista parte registrantur littere sparsse secrete qui commence au folio $317 \mathrm{r}$. Les documents postérieurs relatifs à la legatio confiée à Pere Boïl sont alors enregistrés dans cette section à partir du folio $354 \mathrm{r}$. 
deuxième partie du registre ${ }^{85}$. Les Littere sparsse permettent ainsi à de multiples égards une certaine respiration de l'ordonnancement de l'enregistrement sous les rubriques legatio. Au sein des Registra secreta coexistent et parfois coopèrent donc diverses logiques générales de classement, une classification selon un ordre thématico-chronologique avec les legationes et une classification plus strictement chronologique dans les sections littere sparsse. La communication entre les deux parties des registres demeure cependant relativement faible, et les scribes chargés de l'enregistrement éprouvent visiblement des difficultés pour ordonner certains documents. Parfois à l'origine de ce que nous interprétons aujourd'hui comme des erreurs d'enregistrement, ces difficultés constituent en fait un facteur favorable à l'utilisation d'autres modes de classification au sein de Registra secreta structurés par l'ossature fragile des legationes et des littere sparsse. Les Registra secreta, lieu d'élaboration d'un système d'ordonnancement général de la documentation diplomatique qui témoigne du perfectionnement de la chancellerie royale, abritent aussi un «laboratoire d'expérimentation» de la classification de la documentation diplomatique enregistrée ${ }^{86}$.

\section{LES REGISTRA SECRETA: UN LIEU D'EXPÉRIMENTATION POUR L'ORDONNANCEMENT DE LA DOCUMENTATION DIPLOMATIQUE}

Enregistrer un document dans les Registra secreta, ce n'est pas seulement en conserver une trace authentifiable, mais, comme le suggère un scribe qui justifie l'enregistrement d'une lettre du roi de France pour la seconde fois dans le même registre, c'est aussi rechercher un ordonnancement de la documentation qui rende compréhensible un ensemble, une affaire. $U t$ omnia procedant per ordinem ${ }^{87}$, les scribes multiplient donc à diverses

\footnotetext{
${ }^{85} \mathrm{La}$ «Legatio comissa venerabili G. episcopo Gerundii ad reverendum collegium dominorum cardinalium, sive ad omnes, sive ad particulares, ut inferius continetur» (ACA, C., reg. 337, fol. $342 \mathrm{r}$ ) se trouve ainsi dans la section In ista parte registrantur littere sparsse secrete du registre 337.

${ }^{86}$ Nous adaptons ici une expression employée par O. GUYOTJEANNIN à propos du Trésor des Chartes des rois de France, en lequel il voit «l'un des plus actifs laboratoires archivistiques du Moyen Âge occidental» (O. GUYOTJEANNIN, Les méthodes..., opus cit. (cf. note 17), p. 296).

${ }^{87}$ «Primo igitur, ut omnia procedant per ordinem, fuit hic registrata littera dicti regis Ffrancie, licet iam supra registrata sit, quam aportavit Bernardus de Turri, ut superius est notatum. Cuius tenor sequitur [...]» (ACA, C., reg. 336, fol. 112v). Cette note prélude à l'enregistrement d'une
} 
échelles les expériences de regroupement de la documentation diplomatique enregistrée.

\section{Quelques expériences de rassemblement des documents diplomatiques enregistrés}

Si les années placées en position de titre fournissent quelquefois un repère dans les Registra secreta, la documentation enregistrée n'est par ordonnée sous des rubriques définies de manière chronologique ${ }^{88}$, mais dans des chapitres thématiques. Les rubriques legatio sont alors certes les plus nombreuses à remplir cet office, mais, en particulier au sein des littere sparsse, elles n'éclipsent jamais totalement des Registra secreta les rubriques thématiques plus traditionnelles. Ces dernières adoptent un titre qui indique l'affaire ${ }^{89}$ ou bien le souverain étranger concerné ${ }^{90}$, et abritent sur quelques folios des documents enregistrés de manière essentiellement chronologique. Elles sont utilisées en particulier lorsque le roi ne dépêche aucune ambassade pour répondre à une lettre ou à une ambassade étrangère. Dans ce cas, les réponses aragonaises envoyées par simple courrier ou emportées par

lettre de Philippe IV adressée à Jacques II (26 avril 1313, Poissy), consécutive à la venue de l'ambassade aragonaise menée par Berenguer d'Arguelaguer et Bernat de Torre. Ce deuxième enregistrement est effectué à la suite du retour de Berenguer d'Arguelaguer auprès du roi d'Aragon, alors qu'un premier enregistrement avait déjà été effectué lors du retour de l'autre membre de l'ambassade, Bernat de Torre (ibid., fol. 104r (2), précédé de la note de chancellerie: «Reveniente igitur Bernardo de Turri, scriptore domini regis, de legatione premissa, attulit et presentavit domino regi quamdam litteram illustris regis Ffrancie, cuius series sic se habet»). La lettre de Philippe le Bel elle-même est éditée par J. REGLÀ, opus cit. (cf. note 66), vol. II, app. III, doc. 31, p. 311-312. Sur le contexte de cette affaire, Ibid., vol. I, p. 173-184.

${ }^{88} \mathrm{De}$ manière significative, les années n'apparaissent qu'à deux reprises en position de titre, une première fois en pleine page, en 1293 «Anno Domini M.CC.XC.Tercio» (ACA, C., reg. 252, fol. 71r) et une deuxième fois en 1317 en caractères majuscules entre deux entrées "Anno Domini Millesimo CCC.XVII» (ACA, C., reg. 337, fol. 256v).

${ }^{89} \mathrm{Cf}$. par exemple les rubriques «Super quibusdam tractatibus de quibus agitur inter dominum regem ex una parte et nobiles Artaldum de Luna et dompnam Constanciam uxorem eius ex altera" (ACA, C., reg. 337, fol. 225r), "Super facto desabenencie regis Castelle et infantis Johannis» (ibid., fol. 319r), «Super facto gentis armigere ire debentis ad regis Roberti servicia cum Guilaberto de Scintillis et Francisco Pandoni, de quo supra iam habetur» (ibid., fol. 323r); «Super facto cambii Vici» (ibid., fol. 326r).

${ }^{90} \mathrm{Cf}$. par exemple les rubriques «Inter dominum regem nostrum et illustrem regem Ffredericum» (ACA, C., reg. 334, fol. 162r, se rapporte aux folios 162r-170v et à des documents qui vont du 9 juin 1303 au 26 octobre 1306) et «Inter dominum regem et regem Abenjacob» (ibid., fol. $171 \mathrm{r}$, se réfère aux folios $171 \mathrm{r}-175 \mathrm{v}$ avec des documents datés du 20 septembre 1303 au 20 août 1304). 
l'ambassadeur étranger qui repart ne s'intègrent en effet que difficilement sous les rubriques legatio ${ }^{91}$. Les réponses formulées par Jacques II peuvent alors être rassemblées sous une même tête de chapitre $e^{92}$, mais, et c'est là le phénomène le plus notable, leur enregistrement est parfois précédé de la copie ou de la mention de la lettre étrangère reçue, elle-même encadrée de notes de chancellerie:

Cum dominus rex recepisset ab illustri rege Ffrancie quandam litteram suam per manus Raimundi de Melanno, cuius littere tenor sequitur in hunc modum:

Tres chiers e amez cousins, vous envoions par devers vous notre ame e feal chier Raymont de Mallan pour traitier du mariage de notre chier frere Charle de Evreux e de votre fille, si vous prions chierement que vous le veulliez creire de ce quil vous dira de par nous sus ceste chose. Donne a Sant Christofle en Balare le X. jour de may [1327]

Dominus rex respondit ei per litteram suam traditam dicto Raimundo de Malan, sub forma sequenti (suit la copie de la lettre remise à Ramon de Melany $)^{93}$

La copie dans le Registrum secretum de la lettre de créance du roi de France Charles IV le Bel en faveur de l'ambassadeur Ramon de Melany facilite ici la compréhension de l'enregistrement isolé d'une lettre envoyée en réponse par le roi d'Aragon. Développant cette méthode, les scribes en viennent parfois à rassembler au sein d'un même chapitre les deux parties de la correspondance échangée pendant plusieurs mois entre Jacques II et un

\footnotetext{
${ }^{91}$ Sur les courriers (correos, troteros) au service de Jacques II, cf. J.E. MARTínEZ FERRANDO, Los correos de la curia regia en la Corona de Aragón a principios del siglo XIV, "Analecta Sacra Tarraconensia», XVII (1944), p. 97-113.

${ }^{92} \mathrm{Cf}$. par exemple les réponses de Jacques II à une ambassade de Frédéric III de Sicile sous la rubrique «Littere responsales ad regem Fredericum et quedam alie littere super legatione qua venerunt ad dominum regem pro parte eius frater Peregrinus de Messana de ordine predicatorum et Franciscus de Johanne miles» (ACA, C., reg. 336, fol. 25r).

${ }^{93} \mathrm{ACA}$, C., reg. 339, fol. 260r. Autre exemple de document étranger qui permet de contextualiser l'enregistrement de réponses envoyées par le roi : la copie d'une lettre adressée à Jacques II d'Aragon par Edouard II, roi d'Angleterre, datée du 29 juin 1323 (ACA, C., reg. 338, fol. $65 \mathrm{v}$ ), est précédée de la note "Cum dominus rex recepisset a rege Anglie litteram tenoris sequentis» (ibid., fol. 65v) et suivie de la note «Dominus rex respondit per litteram rescriptivam continentie infrascripte» (ibid., fol. 66r), avant que ne soit enregistrée la lettre de Jacques II au roi anglais (Barcelone, 29 octobre 1323). Dans les registres d'Alphonse IV d'Aragon, F. C. CASUla, opus cit. (cf. note 5), p. 255 note aussi la présence de lettres reçues.
} 
souverain étranger ${ }^{94}$. Alors que les registres demeurent traditionnellement le lieu d'enregistrement des documents émanant de la chancellerie royale, les scribes n'hésitent donc pas à faire figurer dans les Registra secreta la copie d'originaux reçus ${ }^{95}$.

La majorité des tentatives de rassemblement de la documentation diplomatique menées dans les Registra secreta s'efforcent toutefois plutôt d'utiliser ou d'adapter le cadre fourni par les rubriques legatio et les littere sparsse. Les titres des chapitres legatio, assez brefs et standardisés dans les premiers registres de la série, se développent ensuite pour devenir plus explicites sur la documentation à laquelle ils se réfèrent ${ }^{96}$, ce qui conduit parfois, notamment dans l'ultime volume de la série, à la disparition du terme

${ }^{94} \mathrm{Ceci}$ peut conduire dans des cas isolés à l'enregistrement de l'ensemble d'une legatio étrangère, qui sert de prélude à la réponse envoyée par le roi, comme par exemple la «Legatio destinata domino regi Aragonum per illustrem principem Francie regem et responssio ad eandem» (ACA, C., reg. 334, fol. 79r-81r). On trouve sous cette rubrique une lettre de créance de Philippe le Bel pour son ambassadeur auprès de Jacques II (ibid., fol. 79r, 11 août 1302, Paris), une copie des instructions françaises («Haec sunt capitula quae obtulit domino regi dictus nuncius», ibid., fol. 79r-v, éd. (partielle) H. FINKE, Acta Aragonensia, opus cit. (cf. note 5), vol. I, doc. 83, p. 119-121, sans date), puis une lettre de créance en réponse de Jacques II («Responsio domini regis Aragonie ad predicta", ibid., fol. 80r, 18 septembre 1302, sans lieu), des instructions sur l'objet de la mission («Capitula responsiva per dominum regem ad regem Francie», ibid., fol. 80r-v, éd. (partielle) H. FINKE, ibid., vol. I, p. 121 en note), une lettre de Philippe le Bel à Jacques II (ibid., fol. 80v (2), Paris, 28 octobre 1302), la réponse de Jacques II (ibid., fol. 80v (3), Barcelone, 19 novembre 1302) et enfin une lettre adressée par Jacques II à des messagers français (ibid., fol. 81r (1), Barcelone, 19 novembre 1302). Pour un exemple similaire, cette fois-ci avec Gênes, cf. ACA, C., reg. 334, fol. 126r-129r.

${ }^{95}$ Des documents émanant de chancelleries étrangères peuvent aussi être copiés dans les registres lorsqu'ils sont emmenés par des ambassadeurs aragonais pour les besoins de leur mission. Quand Vidal de Vilanova et Guerau de Rocabertí partent en juillet 1318 à la curie pour proposer une médiation aragonaise entre Robert de Naples et Frédéric III de Sicile, ils emportent ainsi plusieurs projets de paix. L'un d'entre eux, envoyé auparavant par Frédéric III de Sicile à Jacques II dans des cahiers (quaternii), est copié pour les ambassadeurs en latin et in vulgari, puis consigné dans le registre en étant précédé de la note suivante: «Subscriptas formas pacis atulerunt et domino regi nostro tradiderunt notarius Michelis de Cantono et Romeus de Arteriis, nuncii missi per dominum regem Ffredericum ad dictum dominum regem nostrum, ut continebantur inter alia in quaternis traditis per ipsos nuncios que habentur, de quibus quaternis fuerunt tradita translata antefatis nobili Geraldo de Rochabertino et Vitali de Villanova. Et etiam eisdem fuit traditum translatum formarum predictarum pacis tam in latino quam in vulgari. Et in latino sunt que sequntur [...]» (ACA, C., reg. 338, fol. 8v).

${ }^{96}$ On trouve par exemple comme titre de chapitre pour une ambassade envoyée en septembre 1324 auprès de Charles de Valois: «Recepta responssiva littera per dominum regem a supradicto Karolo comite Valesii fuit super predicto negocio ordinata et comissa legatio religioso fratri $R$. de Masquefa de ordine predicatorum in qua acta sunt que sequntur» (ACA, C., reg. 339, fol. $351 \mathrm{v})$. 
legatio des rubriques ${ }^{97}$. L'ordonnancement des documents au sein même des chapitres fait lui aussi l'objet d'aménagements. Afin de rendre plus lisible la documentation enregistrée, une sous-rubrique littere sparsse s'immisce ainsi à plusieurs reprises à l'intérieur d'une legatio, le mode de répartition général de la documentation au sein du Registrum secretum est de la sorte adopté au niveau du chapitre ${ }^{98}$. À une échelle supérieure, plusieurs chapitres legatio (ou assimilés) qui se réfèrent à une matière commune peuvent être réunis. Diverses legationes dépêchées auprès de souverains musulmans sont ainsi enregistrées de manière consécutive ${ }^{99}$. Le lien entre plusieurs legationes relatives à une même affaire apparaît alors souvent de manière explicite dans les titres grâce à la mention circa premissa qui renvoie d'une rubrique à une

${ }^{97}$ Pour une mission confiée à Arnau de Cumbí et Pere Despens en décembre 1326, afin de marier l'infant Pedro, fils de Jacques II, et de régler l'affaire du comté d'Empuries, la tête de chapitre s'intitule: «Quando A[rnaldus] de Cumbis, archidiaconus Sancte Marie de Mari in ecclesia Barchinone, et Petrus Despens, jurisperitus, fuerunt missi ad dominum papam tam per dominum regem quam dominum infantem Petrum, fuit tradita dicto A[rnaldo] littera de credencia ad dictum dominum papam super facto comitatus Impuriarum et ipsis Arnaldo et Petro littera de credencia ad ipsum dominum papam super facto matrimonii domini infantis Petris, una cum aliis litteris pro negociis ipsis facientibus, ut infra videbitur» (ACA, C., reg. 339, fol. 229r). Cette rubrique se rapporte à une documentation tout à fait similaire à celle des rubriques legatio: lettres de créance sur l'affaire du comté d'Empuries (ibid., fol. 229r (1-2), 16 décembre 1326, Barcelone) et sur le mariage de l'infant Pedro (ibid., fol. 229r (3), 16 décembre 1326, Barcelone), recommandations auprès de différentes personnalités influentes à la curie (ibid., fol. 229v (1-2), 16 décembre 1326, Barcelone), mention de remise de sauf-conduits (ibid., fol. 229v (3), sans date), instructions aux ambassadeurs (ibid., fol. $229 \mathrm{v}-231 \mathrm{r}$, sans date). D'autres rubriques qui éludent la mention du terme legatio abritent aussi une documentation comparable, «Super negocio matrimonii quod tractatur de nobili Johanne filio infantis Johannis quo de Castella et spectabilem puellam Blancam filiam infantis Petri de Castella bone memorie et domine infantisse Marie eius». uxoris filie domini nostri regis eius dominique domini regis neptem» (ibid., fol. 210r), "Super tractatu matrimoniorum inter dominum infantem Petrum filium domini regis et dominam infantissam Elionor filiam illustris regis Castelle. Et inter primogenitum regis Portugalie et dominam Blancham neptem domini regis nostri »(ibid., fol. 249r), etc.

${ }^{98} \mathrm{C}$ 'est le cas notamment pour l'ambassade de Joan Borgunyó auprès de Frédéric III de Sicile et de Robert de Naples déjà évoquée (cf. note 36): la "Legatio comissa per dominum regem nostrum discreto Johanni Burgundi, sacriste Maiorice ad illustrem dominum regem Ffredericum» (ACA, C., reg. 337, fol. 211v) comporte une sous-section «Littere sparse super eodem» (ibid., fol. 215r), de même que la «Legatio comissa per dominum regem nostrum discreto Johanni Burgundi, sacriste Maiorice ad illustrem dominum regem Robertum» (ibid., fol. 216r): «Littere sparse super predictis» (ibid., fol. 217r).

${ }^{99} \mathrm{Cf}$. ACA, C., reg. 338, fol. 138r-151v où se trouvent des legationes dépêchées en Égypte, à Tunis, au Maroc et à Bougie. Cependant, aucun terme du registre ne relie de manière explicite ces chapitres entre eux. 
autre et contribue à définir au sein des registres des ensembles plus vastes que les chapitres legatio ${ }^{100}$.

Les Registra secreta constituent donc un lieu d'expérimentation des modes de regroupement de la documentation diplomatique enregistrée très productif. Pour cette raison précisément, il est assez difficile de s'orienter à l'intérieur des registres, car les critères et les méthodes retenus pour ordonner la documentation s'avèrent extrêmement variables. Sans aucun doute conscients du problème, les scribes de la chancellerie ont par conséquent utilisé et développé de nombreux renvois internes qui devaient aider à retrouver la documentation enregistrée et à lutter contre la dispersion de l'information relative à une même affaire.

\section{D'un document à l'autre: circuler dans les Registra secreta}

Encore très peu nombreux dans le registre 252 (1292-1300) dont l'organisation s'articule essentiellement autour des rubriques legatio, les renvois internes se développent à partir du deuxième volume de la série, lorsque l'ordonnancement de la documentation devient plus complexe. Les rubriques, on l'a vu, se réfèrent à d'autres rubriques et esquissent ainsi des ensembles documentaires plus larges. Ces renvois à d'autres parties du registre s'effectuent soit par référence explicite à la rubrique précédente (circa premissa), soit par l'indication de nombre de folios ${ }^{101}$ ou d'entrées du registre ${ }^{102}$ qui séparent du chapitre mentionné. À une échelle inférieure, des

\footnotetext{
${ }^{100} \mathrm{Par}$ exemple, la tête de chapitre «Legatio circa premissa comissa Gondiçalvo Garsie et Johanni Bergundi sacriste Maiorice et canonico valentino, ut inferius plenius continetur» (ACA C., reg. 335, fol. 208r) se réfère à celle qui la précède dans le registre «Legatio comissa Johanni Burgundi sacriste Maiorice et Thome de Prochida ad regem et reginam Ffrancie ut infra patet» (ibid., fol. 202r). De même, la «Legatio circa premissa comissa venerabili Micheli de Turrali archidiacono Daroce in ecclesia Cesaugustana ad inclitum Karolum comitem Valesie et ad alios, ut inferius apparebitur» (ACA, C., reg. 338, fol. 102r) se réfère à "Circa negotium motorum tractatuum de matrimonio contrahendo inter dominum Karolum regem Ffrancie et Navarre et dominam Jolant filiam domini regis nostri et domine regine Blanche bone memorie conjugis sue» (ibid., fol. 101r).

${ }^{101}$ Le titre «Continuatur hic super legatione qua missus est ad reges Portugalie et Castelle Boshom Eximini de consilio domini regis, de qua habetur supra in XX primo folio» (ACA, C., reg. 339, fol. 257r) renvoie ainsi à la «Legatio comissa ad reges Castelle et Portugalie circa premissa Boshom Eximini de consilio domini regis» (ibid., fol. 236r).

${ }^{102} \mathrm{C}$ 'est par exemple le cas de la note «De hiis que aguntur inter dominos reges nostrum et Ffrancie ac Maioricarum, super quibus iam habetur supra in VI carta in precedentibus" (ACA, C., reg. 337, fol. 264r).
} 
notes de chancellerie apposées au-dessus, au pied ou plus rarement en marge des documents enregistrés peuvent aussi renvoyer à des documents situés ailleurs dans le registre ${ }^{103}$, voire dans d'autres registres de la chancellerie ${ }^{104}$. La circulation au sein des Registra secreta est aussi facilitée par des notes de chancellerie justificatives qui rendent explicites les mobiles de transcriptions susceptibles de modifier l'économie interne des registres. L'enregistrement d'un document se justifie ainsi de manière significative par le souci de réunir en un même endroit du registre la documentation portant sur une même affaire $^{105}$. Comme certains documents présentent des intérêts multiples, les scribes choisissent parfois de les enregistrer à deux reprises, d'où la confection de notes de renvoi réciproque entre deux copies du même acte ${ }^{106}$.

\footnotetext{
${ }^{103} \mathrm{Ce}$ renvoi à un document déjà enregistré s'effectue notamment pour l'expédition d'une copie, ici incluse dans une autre lettre enregistrée: «In predicta littera fuit missus interclusus tenor littere regis misse domino pape, de qua supra sit mentio, qua registrata est supra sub datum Barchinone X kalendas septembris anno predicto» (ACA, C., reg. 338, fol. 17r), qui renvoie ainsi par sa date (sans année) à une autre entrée du registre (ibid., fol. 12v-13r, 23 août 1318, Barcelone: lettre de Jacques II au pape Jean XXII).

${ }^{104} \mathrm{De}$ retour d'une mission auprès du roi de Majorque effectuée en juillet 1318 , Guillem Oulomar rapporte ainsi des accords passés avec ce dernier, dont la copie dans un registre Solutionum est indiquée dans une note du Registrum secretum: «Reveniente autem dicto Guillelmo Oulomarii de legatione premissa, atulit ordinationem eorum que fecerat cum dicto rege Maioricarum, videlicet quod fieret carta sicut et facta fuit et missa dicto regi Maioricarum per quam dominus rex noster recognovit debere dicto regi Maioricarum septem milia librarum barchinonensium pro custodia vallis de Aranno et Castri Leonis. Que promisit sibi solvere per certos terminos, datis obsidibus, ut in ipsa carta qua datur fuit in Orta sextodecimo kalendas augusti anno Domini Millesimo Trecentesimo Tertiodecimo. Registrata in registro solutionum que ut omnia hic contineantur pro memoria fuit hic registrata[...]» (ACA, C., reg. 336, fol. 110v souligné par nous). Des documents enregistrés dans les registres Curiae sont aussi indiqués: "Certum est quod littere due de quibus in dicta littera dicitur, altera quarum domino pape, et altera domino cardinali de Pelagrua diriguntur, registrata sunt in registro curie» (ACA, C., reg. 337, fol. 171r, souligné par nous).

${ }^{105} \mathrm{Cf}$. par exemple la note qui suit l'enregistrement de deux lettres relatives aux tentatives de médiation de Jacques II d'Aragon entre Frédéric III de Sicile et Robert de Naples en décembre 1316: «Predicte due littere fuerunt hic registrate, quia tangunt negocium regum Roberti et Ffrederici» (ACA, C., reg. 337, fol. 308v). Ce souci se retrouve aussi à l'échelle de la rubrique, comme le prouve celle qui suit: «Legatio comissa venerabili in Christo patri Poncio, Barchinone episcopo, et Vitali de Villanova, militi, ad sanctissimum patrem dominum Johannem noviter in papam creatum. Qua hic ideo registrata est, ut inveniantur simul ea que faciunt pro facto bonorum templi quondam, licet alia plura contineantur in ea ut inferius continetur» (ibid., fol. $173 r$, souligné par nous).

${ }^{106}$ Le souci d'indiquer le double enregistrement de documents conduit parfois à une prolifération de justifications: trois lettres adressées à Frédéric de Sicile, qui relèvent de la rubrique «Circa negocium regis Ffrederici» (ACA, C., reg. 338, fol. 28r) sont ainsi précédées de la notice «Predicte tres littere proxime registrate similiter registrate sunt infra in rubrica legationis Simonis de Bello Loco» (ibid., fol. 34r) qui renvoie à la rubrique «Legatio principaliter per dominum infantem Alfonsum et consequenter per dominum regem comissa Simoni de Belloloco consiliario domini regis ad dominum papam et ad regem Robertum» (ibid., fol. 52r),
} 
Corrélativement, si l'enregistrement au lieu escompté est rendu impossible par manque de place, une note de chancellerie précise par l'indication du folio ou de la rubrique où le trouver dans le registre, alors qu'une note de renvoi est apposée auprès de la transcription effectuée ${ }^{107}$. Les renvois réciproques entre documents enregistrés ou entre rubriques se multiplient donc à la fin du règne, et l'on assiste même à l'apparition de renvois à plusieurs parties distinctes du registre dans une même rubrique ${ }^{108}$.

Face au perfectionnement des renvois internes par notes ou par rubriques, les quelques dessins qui indiquent des actes enregistrés font pâle figure. Une première initiative graphique surmonte la copie d'une lettre adressée au roi Philippe le Bel par Jacques II en août 1302: deux écus triangulaires sont assez grossièrement dessinés, l'un qui représente avec des barres le blason de Jacques II, et l'autre aux armes du roi de France, avec un semis de fleurs de lys ${ }^{109}$. L'idée sous-jacente semble bien ici de figurer les armes du rédacteur et du destinataire de la lettre, mais il s'agit plus d'une tentative isolée que d'un élément d'une sémiotique graphique ${ }^{110}$, dont pourtant des exemples contemporains sont attestés à la chancellerie royale aragonai$\mathrm{se}^{111}$. De manière significative, la dernière représentation graphique que l'on

où l'on retrouve effectivement les lettres, précédées de la note «Certum est quod subscripte tres littere consequenter registrate sunt similiter registrate supra inter alias sub rubrica "circa negocium regis Ffrederici"» (ibid., fol. 57v), mais ... suivies d'une note similaire, d'une autre encre: «Predicte tres littere supra proxime registrate sunt similiter supra alibi registrate in rubrica ubi dicitur "circa negocium regis Ffrederici"» (ibid., fol. 58r).

${ }^{107} \mathrm{Ceci}$ apparaît clairement dans la note suivante: «Certum est quod super premissis negociis, cum hic registrari non possent, fuit recepta alia pars huius registri ad haec registranda, qua est infra in XLVII ${ }^{\circ}$ carta» (ACA, C., reg. 338, fol. 62v), quarante-sept folios plus loin, on trouve les documents qui devaient être enregistrés, précédés de la rubrique suivante: "Continuatio legationis comisse ad dominum papam et ad regem Robertum Simoni de Bello Loco, super negociis ipsius regis et regis Ffrederici et aliis de quibus habetur supra in L carta et sequentibus» (ibid., fol. 110r) [le renvoi est effectué au folio 60v, car c'est le début de la «Legatio comissa ad dominum papam Johannem Simoni de Bello Loco consiliario domini regis»].

${ }^{108}$ «Super isto negocio infra registratum est in $\mathrm{XII}^{\circ}$ folio et sequentibus et etiam supra tangitur aliquid de isto negocio in XIII ${ }^{\circ}$ folio et sequentibus» (ACA, C., reg. 339, fol. 238v), qui renvoie à des documents qui se trouvent enregistrés avant et après dans le registre.

${ }^{109} \mathrm{ACA}, \mathrm{C}$, reg. 334, fol. 77r.

${ }^{110}$ Une autre tentative similaire accompagne avec une croix et un écu aux armes de Jacques II l'enregistrement d'une lettre adressée par le souverain aragonais au pape (ACA, C., reg. 334, fol. 181r).

${ }^{111}$ Notamment dans l'un des Memoriales de Mateu Botella, ACA, C., Memoriales, 7/1 (inventaire de 1306). Cf. J. RIERA I SANS, Catálogo de memoriales e inventarios siglos XIV-XIX, Madrid: Ministerio de Educación y cultura, 1999, notice [5], p. 24; R. CONDE Y DELGADO DE MolinA, Les primeres Ordinacions, opus cit. (cf. note 18). Sur le rôle des symboles graphiques 
trouve dans les Registra secreta, une nouvelle fois une fleur de lys, n'exerce guère qu'une fonction décorative. Accompagnant une notice de renvoi au folio en elle-même suffisante pour retrouver la documentation à laquelle elle se réfère, la fleur de lys sert uniquement à faciliter le repérage ${ }^{112}$, le signum graphique demeure réellement «en marge des formalités habituelles de la chancellerie» ${ }^{113}$, c'est-à-dire de la référenciation par l'écriture et le chiffre. L'ensemble des repères, renvois et références internes aux registres démontre en tout cas l'importance du travail de révision et de mise à jour effectué lors de la transcription de nouveaux actes, dont l'enregistrement a de plus en plus fréquemment pour conséquence la rédaction d'une note de chancellerie auprès d'un document déjà enregistré. Les liens entre les différentes entrées du registre se sont donc considérablement renforcés et les documents diplomatiques sont rassemblés, repérés de manière plus précise, il ne reste plus désormais qu'un pas à franchir: relier les documents au sein de récits.

\section{Les Registra secreta producteurs de récits?}

Les notes de chancellerie indiquent, justifient, ou bien encore renvoient à un acte enregistré, mais elles jouent aussi d'autres rôles dans les Registra secreta. Alors que les documents regroupés sous une rubrique legatio se succèdent dans le premier Registrum secretum (1292-1300) sans autre lien visible que leur commune appartenance à un même chapitre, de brèves notes de chancellerie apparaissent et se généralisent dès le deuxième registre de la série pour signifier avant l'enregistrement d'un document qu'il est remis à un

dans les actes médiévaux, cf. P. RücK (éd.), Graphische Symbole in mittelalterlichen Urkunden. Beiträge zur diplomatischen Semiotik, Sigmaringen: Jan Thorbecke Verlag (Historische Hilfswissenschaften 3), 1996.

${ }^{112}$ La première fleur de lys se trouve à côté de la note de chancellerie "Quia hac pars non poterat capere plus negociorum legationis predicte, fuit infra continuatum negocium in lxxvii carta in prima pagina cuius est tale signum» [suit la fleur de lys] (ACA, C., reg. 337, fol. 190v) qui clôt la première partie de l'enregistrement de la documentation d'une ambassade confiée à Vidal de Vilanova auprès du pape en février 1317. On retrouve effectivement soixante-dix sept folios plus loin le renvoi par le folio et la fleur de lys «Super negociis legationis pro qua Vitalis de Villanova consiliarius domini regis est in curia domini pape. Estque alia prior pars ipsius legacionis supra ac finit in lxxvii carta ubi est tale signum» (ibid., fol. 267r).

${ }^{113} \mathrm{~J}$ 'emprunte cette expression à D. NAVARRO BoNILLA, Manifestaciones gráficas ordinarias (Zaragoza, siglos XVy XVI), «Signo. Revista de Historia de la Cultura Escrita», 5 (1998), p. 161162. 
ambassadeur ${ }^{114}$. Le rassemblement diachronique et thématique sous une seule tête de chapitre (legatio ou autre) d'un ensemble de documents a dès lors parfois pour conséquence un développement remarquable des notes de chancellerie. Plus précises dans leur contextualisation des documents enregistrés ${ }^{115}$, elles peuvent même rapporter un événement sans se référer de manière explicite à une entrée du registre. Elles indiquent l'existence d'instructions orales du roi à ses ambassadeurs ${ }^{116}$, mentionnent une conversation de Jacques II avec des ambassadeurs étrangers ${ }^{117}$, certifient le retour d'un ambassadeur et le résultat de sa mission ${ }^{118}$, ou bien encore attestent du rapport

\footnotetext{
${ }^{114} \mathrm{Ces}$ notes suivent un modèle assez stéréotypé (fuit tradita etc.). Un exemple significatif en est fourni par les notes qui accompagnent la remise de documents diplomatiques à Artal de Azlor et Sancho Garcés de Loriz qui doivent se rendre en Castille en avril 1303 «Originale autem littere predicte fuit traditum per Petrum Martinum scriptorem domini regis Artaldo d'Azlor et Sancio Garcesii de Loriz nunc nunciis ordinatis super negocio supradicto, ut inferius patet.

Deinde dictus dominus rex noster (ordinavit nuncios barré) elegit et ordinavit nuncios subs[-] iturum ad predictum negocium infra nominatos, quibus fieri jussit et tradi procuratorium sequens» (ACA, C., reg. 334, fol. 110r-v) (suit le pouvoir en question) [...]

Item fuit tradita dictis nunciis littera credencie ad inclitum dompnum infantem Enrricum sub sequenti forma (ibid., fol. 111r) (suit la lettre de créance) [...]

Item fuerunt tradita dictis nunciis capitula sequentia (ibid., fol. 111v) (suivent les instructions)

Item fuit tradita eisdem nunciis litera guidatici de qua supradicitur, dictata sub forma sequenti» (ibid., fol. 112r) (suit le guiatge, c'est-à-dire ici le sauf-conduit).

${ }^{115}$ Les notes de contextualisation sont particulièrement détaillées dans le cas de l'enregistrement d'un document qui n'émane pas de la chancellerie (cf. supra l'exemple de la lettre de créance de Ramon de Melany) et lorsqu'il s'agit d'une réponse à une ambassade étrangère. Une note peut mentionner la venue de l'ambassade pour contextualiser la réponse du roi: «Quando venerunt ad dominum regem cum littera credencie Alvar Juanyes scriptor nobilis Johannis de Biscaya et Johannes Ferdinandi scriptor domine infantisse Marie ex parte dicti Johannis

Sub titulo sequenti ordinavit dominus rex scribi nunc dicto nobili Johanni (suit la lettre au noble castillan Juan de Viscaya), ACA, C., reg. 339, fol. 214r.

${ }^{116} \mathrm{ACA}, \mathrm{C}$. , reg. 334 , fol. $8 \mathrm{v}$.

${ }^{117} \mathrm{ACA}, \mathrm{C}$, reg. 336, fol. 125r.

${ }^{118} \mathrm{La}$ «Continuatio legationis comisse ad dominum papam et ad regem Robertum Simoni de Bello Loco, super negociis ipsius regis et regis Ffrederici et aliis de quibus habetur supra in $\mathrm{L}$ carta et sequentibus» (ACA, C., reg. 338, fol. 110r, cf. note 107) se clôt ainsi par une note signifiant l'échec de l'ambassade qui devait ramener la paix entre les rois de Sicile et de Naples: «Certum est quod predictus Simonis de Belloloco rediit de dicta legatione. Et in facto pacis dictorum regum Roberti et Ffrederici nichil fuit effectum» (ibid., fol. 114v (1)). Un autre exemple est fourni par cette note inscrite au retour de Guerau de Rocabertí et Vidal de Vilanova de leur ambassade à la curie: «Certum est quod subscripti nobilis Geraldus de Rochabertino et Vitalis de Villanova redierunt de curia domini pape et nulla alia expeditio fuit facta, quia rex Robertus non venerat, dum ipsi fuerunt ad curiam domini pape» (ibid., fol. 17v).
} 
final viva voce effectué par les représentants du roi au retour de leur ambassade ${ }^{119}$.

La trame décousue des régestes et des transcriptions de documents réunis sous les rubriques gagne ainsi en continuité narrative. Prenons l'exemple du chapitre intitulé Inter dominum regem et regem Maiorice, qui renferme sur trois folios des documents datés du 18 janvier au 23 juillet 1321 , presque tous relatifs au renouvellement de l'hommage pour fief dû par le roi Sanche de Majorque au roi d'Aragon. Notes de chancellerie et copies de lettres reçues du roi de Majorque alternent ici avec les entrées d'actes expédiés par la chancellerie aragonaise ${ }^{120}$. Le changement d'encre permet de

\footnotetext{
${ }^{119}$ De retour au début du mois de mars 1305 d'une mission auprès du roi de France, Joan Borgunyó et Tomaso di Procida relatent au roi leur échec et la teneur de leurs conversations avec Philippe le Bel: «Postmodum cum dicti nuncii rediissent negocio inperfecto, sic tamen quod refferentes explicationem legationis sue dixerint inter cetera regem Francie debere suum nuncium destinare in proximo dicto regi nostro.[...]» (ACA, C., reg. 335, fol. 206r). Autre exemple, ACA, C., reg. 339, fol. 389v.

${ }^{120}$ «Inter dominum regem et regem Maioricarum Nobilis Guillelmus de Caneto et Nicholaus de Sancto Iusto, thesaurarius illustris Sancii regis Maioricarum, venerunt ad dominum regem in civitate Valencie ex parte dicti Maioricarum regis et presentaverunt ei quandam litteram clausam dicti regis Maioricarum suo sigillo sigillatam, cuius tenor talis est: (fol. $76 r$ )

(suit la lettre de créance du roi Sanche de Majorque pour ses deux ambassadeurs, Perpignan, 18 janvier 1321)

Predicti autem nuncii venerunt pro negocio potestatum Maioricarum et aliarum terrarum, quas dictus rex Maiorice tenet pro domino rege in feudum, et super facto adventus dicti regis Maioricarum ad curias domini regis nostri ut tenetur secundum convenencias.

Et inter dominum regem ex una parte et dictos nuncios ex altera fuerunt habiti tractatus super predictis duobus sub forma inferius contenta, quam dicti nuncii portaverunt secum in quadam cedula, cuius tenor sequitur:

(suit la copie de la cédule: deux méthodes sont proposées au roi de Majorque afin qu'il n'ait plus à venir aux Cortes du roi d'Aragon pour prêter hommage de fidélité. Soit il paie 40000 livres de Barcelone au roi d'Aragon, soit il vient aux prochaines Cortes du roi d'Aragon pour lui demander cette faveur, qui lui sera octroyée grâcieusement)

Quibus tractatibus habitis, dominus rex noster rescripsit regi Maioricarum per litteram suam, traditam predictis nunciis sub forma sequenti: (fol. $76 \mathrm{v}$ )

(copie de la lettre du roi d'Aragon au roi de Majorque: il envoie sa réponse par les ambassadeurs du roi de Majorque, Valence, 13 février 1321)

Bernardus de Aversone mandato regis et fuit suo mandato expedita absque vicecancellario. (changement d'encre)

Postea prefatus Maioricarum rex rescripsit domino regi super predictis per litteram suam continentie subsequentis allatam per predictos nobilem Guillelmum de Caneto et Nicholaum de Sancto Justo: $($ fol. $76 \mathrm{v}$ )

(copie de la lettre du roi de Majorque au roi d'Aragon: il choisit la deuxième voie et exige la confirmation de l'offre, Perpignan, 21 mars 1321)

Ad quae dominus rex noster rescripsit dicto regi Maioricarum, ut sequitur: (fol. 77 r)

(copie de la lettre du roi d'Aragon au roi de Majorque: il a reçu sa réponse positive par les ambassadeurs, se montre satisfait et lui signifie son accord en lui demandant de venir aux Cortes. Valence, 31 mars 1321)

Bernardus de Aversone mandato regis, cui fuit lecta et expedita vicecancellario mandato regis eidem Bernardo facto.
} 
reconnaître que la transcription a été effectuée en deux phases. Dans un premier temps, une note de chancellerie indique la venue de représentants majorquins porteurs d'une lettre de Sanche, qui est retranscrite et suivie d'une autre note explicitant les raisons de l'ambassade. Une note distincte mentionne alors l'existence de tractatus entre Jacques II et les Majorquins auxquels le roi remet des propositions, consignées ensuite dans le registre. Après une note qui atteste de la rédaction par Jacques II d'une réponse à Sanche et de sa remise aux ambassadeurs, la première phase de transcription se clôt par l'enregistrement de cette même lettre, datée du 13 février 1321. D'une encre différente, une note de chancellerie précise que Sanche a écrit à Jacques II une lettre super predictis, celle-ci est ensuite copiée dans le registre avant qu'une dernière note n'annonce la réponse aragonaise, dont l'enregistrement met un terme à l'échange épistolaire sur cette affaire.

Les notes de chancellerie articulent entre eux de manière remarquable les différents documents transcrits sous la rubrique en annonçant leur enregistrement (ut sequitur), elles rendent possible une continuité narrative par l'usage d'adverbes de temps (postea) ou par des références aux actions passées (Super predictis; Quibus tractatibus habitis) et mettent l'accent sur le rôle des intermédiaires pour contextualiser l'enregistrement des lettres. Cette partie du chapitre, plutôt que comme un recueil de correspondance, peut dès lors être lue comme un récit historique sommaire des relations des rois de Majorque et d'Aragon. Cependant, l'effort des scribes pour relier entre eux les documents atteint rapidement ses limites: au sein même du chapitre Inter dominum regem et regem Maiorice, la dernière lettre du roi d'Aragon enregistrée n'est liée par aucune note de chancellerie aux précédentes ${ }^{121}$. Le récit est donc bien présent dans les Registra secreta, mais il demeure à l'état expérimental et fragmentaire. L'appréciation portée par Pere Benet sur les Secretorum et les Legationum (c'est-à-dire pour le règne de Jacques II sur les Registra secreta) dans un inventaire des Archives royales de Barcelone en 1601 prend dans cette perspective un relief singulier:

(suit une lettre du roi d'Aragon au roi de Majorque sur une autre affaire. Gérone, 17 juillet 321) (ACA, C., reg. 338, fol. 76r-78v). 1321).

${ }^{121} \mathrm{ACA}, \mathrm{C}$. , reg. 338, fol. 78v (lettre de Jacques II à Sanche de Majorque, Gérone, 17 juillet 


\begin{abstract}
Legationum et Secretorum. Si algú dessitja fer la veritable i absoluta història dels reis d'Aragó sense l'estudi d'aquests registres i d'altres similars fracasarà. Per això el diligentíssim autor Jeroni Çurita en els seus Annals, no comet els errors que comet algú dels nostres, per què és fama que va tenir-ho en comte» ${ }^{122}$.
\end{abstract}

La documentation consignée dans ces registres constitue pour Pere Benet une source indispensable pour l'écriture de l'histoire «véritable et absolue» des rois d'Aragon, mais les liens créés entre les documents enregistrés apportent eux aussi une aide précieuse à l'historien. La contextualisation d'un document au moment de sa consignation dans le registre et son intégration au sein d'ensembles plus vastes s'apparentent en effet de manière modeste au travail de Jeronimo Zurita, car l'historien aragonais inclut souvent des documents d'archives dans ses Anales ${ }^{123}$. Cependant, si l'ordonnancement de la documentation enregistrée peut conduire à la constitution de récits fragmentaires au sein des Registra secreta, l'enregistrement d'un document n'a pas pour but premier son insertion au sein d'une narration historique. Les multiples expériences effectuées pour rassembler, ordonner, référencer et repérer les documents consignés dans les Registra secreta témoignent certes d'un travail de composition bien réel, qui doit faciliter la manipulation des registres, mais cet effort d'organisation n'explique pas les mobiles de la transcription des documents diplomatiques. Il faut en fait pour tenter de résoudre ce problème changer d'échelle d'analyse, abandonner la variété des rassemblements documentaires pour se placer au niveau des documents eux mêmes: pourquoi les documents diplomatiques sont-il enregistrés dans les Registra secreta et quel(s) rôle(s) jouent ces registres à leur égard?

${ }^{122} \mathrm{R}$ CONDE y DELGADo DE Molina, La búrxula del present Arxiu Real de Barcelona, de Pere Benet (1601). Primera guia de l'Arxiu, «Lligall», 13 (1998), p. 21.

${ }^{123} \mathrm{Cf}$. de manière générale, B. GUENÉE, Histoire et culture historique dans l'Occident médiéval, Paris: Aubier Montaigne (Collection Historique), 1980, en particulier p. 91-100. Sur l'utilisation de documents d'archives par J. Zurita, cf. A. CANELLAS, Datos para la historia de los reinos peninsulares en el primer tercio del siglo XIV. Dieciocho nuevos documentos de la alacena de Zurita, «Biblioteca de la Real Academia de la Historia», CXLV (1959), p. 231-286; IDEM, Fuentes de Zurita: documentos de la alacena del cronista relativos a los anos 1302-1478, "Cuadernos de Historia Jeronimo Zurita» (1971), p. 157-180. 


\section{LES REGISTRA SECRETA: UN INSTRUMENT DE CONTRÔLE DES USAGES DES DOCUMENTS DIPLOMATIQUES}

De même que l'ensemble des registres de la chancellerie, les Registra secreta servent d'abord à conserver dans la mémoire administrative une trace authentifiée d'actes expédiés au nom du roi. Plus spécifiquement, la tenue de ces registres atteste cependant aussi de la très grande attention portée par les scribes à l'élaboration, à la destination et à l'utilisation des documents diplomatiques qui y sont enregistrés. Les Registra secreta peuvent alors être envisagés conjointement comme un instrument du contrôle exercé par la scribania du roi sur les documents diplomatiques et comme une source sur les usages de cette documentation.

\section{Contrôler l'élaboration et la remise des documents diplomatiques}

Les Registra secreta témoignent tout d'abord très nettement du contrôle exercé par le roi sur l'élaboration de la documentation diplomatique. Prenons l'exemple du registre 338 (1318-1327). Sur les 601 entrées qui s'y trouvent, 532 sont accompagnées de mentions hors-teneur, et 525 d'entre elles résultent d'un mandat direct ordonné par le roi. Les résultats obtenus par $\mathrm{R}$. Conde sur le registre 235 (Curiae I) fournissent ici un point de comparaison intéressant: le pourcentage de mentions hors-teneur présentes dans chacun des registres est tout à fait similaire, mais le roi effectue dans le Registrum secretum des mandats directs dans une proportion trois fois plus importante ${ }^{124}$. Le rôle du roi dans la correction et le suivi des documents s'avère lui aussi bien plus déterminant que dans le registre Curiae, puisque près de la moitié des documents enregistrés (289) sont lus, écoutés, ou corrigés par Jacques $\mathrm{II}^{125}$.

${ }^{124} \mathrm{R}$. CONDE, La transmisión de la jussio regis..., opus cit. (cf. note 8), p. 83-85.

${ }^{125}$ Nous faisons entrer dans cette catégorie les mentions hors-teneur qui comportent l'expression «fuit ei [Jacques II] lecta» ou une expression équivalente et celles qui indiquent une correction personnelle apportée par le roi. Le contrôle exercé par le roi sur les documents diplomatiques apparaît aussi dans les notes de chancellerie particulièrement détaillées qui accompagnent certaines entrées du registre. Jacques II peut ainsi réexaminer les chapitres des instructions et ordonner d'y apposer des corrections: "Ordinata itaque legatione predicta, ut 
Les Registra secreta révèlent donc l'attention particulièrement tatillonne portée par le roi «papelista» ${ }^{126}$ à la rédaction des documents diplomatiques, qu'il semble considérer comme un domaine réservé. La tenue des registres elle-même joue néanmoins ici un rôle spécifique dans le contrôle de l'élaboration documentaire. Cette fonction transparaît notamment dans les notes de chancellerie qui accompagnent les différentes versions enregistrées d'un même acte, lorsque celui-ci subit des corrections. Dans le cas fréquent où des instructions à des ambassadeurs sont corrigées alors qu'une première version a déjà été enregistrée, une note de chancellerie est ainsi apposée auprès de la première entrée pour signifier qu'elle est devenue caduque et renvoyer à la version qui a effectivement été expédiée, la finalis informatio ${ }^{127}$. Les Registra secreta abritent des documents diplomatiques dont ils garantissent l'authenticité, mais l'actualisation des registres et la réécriture constante dont ils peuvent être l'objet doivent aussi permettre de vérifier à tout moment quelle version d'un acte a finalement été retenue pour son expédition ${ }^{128}$.

superius continetur, dominus rex voluit iterum examinare capitula supradicta et propterea fuerunt lecta coram eo in consilio et correxit eadem capitula sub forma sequenti, aliquibus detractis et aliquibus correctis, ut inferius plenius continetur» (ACA, C., reg. 337, fol. 237r, suivi d'une deuxième version des instructions remises à Joan Borgunyó et Bernat Sa Portella au début du mois d'octobre 1314). L'intervention du roi dans la préparation des ambassades apparaît aussi dans des notes qui indiquent un dialogue préalable avec ses représentants, cf. ACA, C., reg. 336, fol. $150 \mathrm{v}$.

${ }^{126}$ Selon l'expression de F. Udina MARTORELl, opus cit. (cf. note 18), p. 27.

${ }^{127}$ Après une première version d'instructions remises à Vidal de Vilanova pour une mission auprès du pape en mars 1310 (ACA, C., reg. 335, fol. 351v), la note de chancellerie suivante a été apposée auprès du titre («Informatio autem tradita dicto Vitali de Villanova sequitur»): «Postea vero hac informatio fuit correcta et in pluribus mutata, ut patet inferius ubi latius registrata est, sicquod non hac, set illa fuit tradita Vitali de Villanova" (ibid.), la version définitive des instructions emmenées par Vidal de Vilanova se trouvant trois folios plus loin, après la note "Sequitur finalis informatio tradita Vitali de Villanova» (ibid., fol. 354r). Une autre correction d'instructions à des envoyés du roi a lieu au retour de Gaston, évêque de Huesca et de Berenguer de Sant Vicenç d'une ambassade auprès du pape. Jean XXII leur a intimé l'ordre d'aller rencontrer le roi Frédéric III de Sicile avant le roi Robert de Naples pour ramener la paix entre eux, les instructions qui leur avaient été remises par Jacques II pour agir auprès des deux rois doivent donc être modifiées. Une note de chancellerie le précise: «Cum venerabilis Gasto, Oscense episcopus, et Berengarius de Sancto Vicencio nuncii supradicti ivissent ad dominum papam et revenissent ab eo, qui ordinavit, quod ipsi nuncii prius irent ad regem Ffredericum quod ad regem Robertum; proptera fuerunt recuperate ab ipsis nunciis omnes predicte littere [instructions, lettres de créance], que fuerunt lacerate et alie facte ipsi regi et aliis sub forma sequenti. Ordinato quod ipsi nuncii primo accedere debeant ad dictum regem Ffredericum et deinde ad dictum regem Robertum» (ACA, C., reg. 339, fol. 200v), les instructions pour l'ambassade à Frédéric III sont aussi corrigées (ibid., fol. 202r).

${ }^{128} \mathrm{~A}$. Kiesewetter remarque de manière similaire pour les registres angevins: «Numerose notizie annotate al margine nei registri stessi da utenti posteriori sottolineano come questi furono uno strumento vivo d'amministrazone e non una fonte custodita in un luogo sperdito e consultato 
Les Registra secreta rendent de surcroît possible un contrôle sur les documents diplomatiques enregistrés qui s'exerce au-delà de la seule élaboration de l'acte. Lorsque des notes de chancellerie signalent la remise d'un document, elles contextualisent certes un enregistrement au sein de chapitres thématiques, mais elles permettent aussi de garder une trace explicite de la destinée du document une fois qu'il a été expédié. Si plusieurs expéditions d'un même acte sont effectuées, les scribes indiquent ainsi de manière significative l'ensemble des personnes qui les reçoivent ${ }^{129}$. En particulier, certaines annotations accompagnant l'enregistrement de lettres adressées à des souverains étrangers révèlent les voies multiples suivies par le courrier diplomatique: les lettres ont été confiées à des marchands ${ }^{130}$, ou bien plus fréquemment à des ambassadeurs étrangers en transit à la cour du roi d'Aragon ou qui repartent auprès de leur mandataire ${ }^{131}$.

D'autre part, les scribes mentionnent aussi dans leurs annotations la remise aux ambassadeurs de documents qui ne sont pas enregistrés dans les

solo di rado» (opus cit. (cf. note 7), p. 373).

${ }^{129}$ Le pouvoir qui fait de Berenguer d'Argelaguer et Pere Despens les commissaires de Jacques II à la conférence de Viella sur le Val d'Aran (ACA, C., reg. 336, fol. 94r (2)-v, 12 juillet 1312, Barcelone) est ainsi suivi de l'annotation «Fuit duplicata», qui indique dans ce contexte qu'un pouvoir identique est remis à chaque représentant du roi. Dans la même perspective, lorsqu'un ambassadeur doit en remplacer un autre, une note spécifie que les documents lui sont remis, précisant le cas échéant les modifications qu'ils ont subies. Dans le cas de Guillem de Santa Coloma, qui doit remplacer Bernat Abbat pour une mission auprès du roi de Majorque en juin 1313 relative au Val d'Aran, les instructions sont traduites -et adaptées- du latin in vulgari (c'est-à-dire ici en catalan): "Informatio tradita Bernardo de Abbate, judici curie, qui fuerat prius ordinatus ad eundum in legatione, postea comissa dicto Guillermo de Sancta Columba, et informatio tradita dicto Guillermo subsequitur infra in vulgari» (ACA, C., reg. 336, fol. 106r, éd. J. REGLÀ CAMPISTOL, opus cit. (cf. note 66), vol. II, app. III, doc. 34, p. 315-316) qui renvoie aux instructions en catalan (ibid., fol. 107r (2)-108r, éd. C. A. WILLEMSEN, opus cit. (cf. note 60), doc. X, p. 218-219). Deux versions du même document, l'une en latin et l'autre en catalan, sont parfois remises aux ambassadeurs. C'est le cas d'un projet de paix entre Robert de Naples et Frédéric III de Sicile confié à Vidal de Vilanova et Guerau de Rocabertí à la mijuillet 1318, pour lequel une note de chancellerie précise: «[...] Et etiam eisdem fuit traditum translatum formarum predictarum pacis tam in latino quam in vulgari. Et in latino sunt que sequntur» (ACA, C., reg. 338, fol. 8v).

${ }^{130}$ Une lettre adressée par Jacques II à Frédéric III est ainsi remise au marchand barcelonais Bernat Fiveller qui se rend en Sicile (ACA, C., reg. 338, fol. 114v (4), 15 février 1323, Barcelone), avant que le roi ne la lui envoie par un autre canal qui n'est pas précisé (ibid., fol. $114 \mathrm{v}(6))$.

${ }^{131}$ Par exemple ACA, C., reg. 339, fol. 241r (remise de lettres datées du 21 août 1327 à Barcelone à un ambassadeur du roi de Sicile qui se rend au Portugal); des instructions peuvent aussi être remises à un ambassadeur étranger lorsqu'il repart ad invicem, comme c'est le cas d'un envoyé du prince de Tarente, qui reçoit des instructions le 18 avril 1327 à Barcelone (ibid., fol. 244r). 
Registra secreta, ils s'y réfèrent soit par l'indication d'un titre qui doit être suffisant pour les identifier ${ }^{132}$, soit par la citation de leur incipit ${ }^{133}$. Réceptacles des versions authentifiées et actualisées des actes expédiés, les Registra secreta servent donc aussi à garder en mémoire à la chancellerie la liste des documents, enregistrés ou non, qui ont été emmenés par les ambassadeurs. Ils contribuent par conséquent aussi bien à contrôler en amont la destinée des documents remis aux envoyés du roi ou à d'autres qu'à délimiter le champ d'action des ambassadeurs sur qui retombe la responsabilité de l'utilisation de cette documentation.

\section{Le contrôle de la documentation diplomatique remise à la chancellerie}

Les notes de chancellerie indiquent quelquefois sommairement les modalités d'usage de la documentation remise, afin de préciser ou de rappeler les instructions adressées aux ambassadeurs. Lorsque le franciscain Ramon de Masquefa se rend en France à la fin du mois d'avril 1325 pour essayer d'obtenir un mariage favorable à l'infant Pedro, il est ainsi muni de divers pouvoirs et lettres de créance, dont la transcription dans un Registrum

\footnotetext{
${ }^{132}$ Pour une ambassade à la curie de l'évêque Pons de Lérida et de Bernat Fonollar, une note de chancellerie indique en février 1309: «Certum est quod fuerunt tradite dictis nunciis omnia predicta [c'est-à-dire les lettres de créance et instructions enregistrées aux folios 257r-259v] Item quadernum indulgenciarium Hospitali concessarum.

Item quaternum den Momelon.

Item tria translata instrumentorum paccionum habitarum inter dominos reges Castelle et Aragonum» (ACA, C., reg. 335, fol. 259v).

${ }^{133} \mathrm{Par}$ exemple pour l'abbé de Santes Creus qui doit se rendre à Montesa avec Guillem de Jafré, juge de cour, en mai 1319, une des très rares notes de chancellerie en catalan des Registra secreta précise la liste des documents que Bernat d'Aversó leur remet, avant qu'une autre note ne précise les conditions de leur utilisation: «Són liurats per en Bernat d'Averçó al abat de Valldigna, liurados per ell al abat de Sentes Creus, lo rescrit papal de la fundacio del monestir qui comença «Johannes, etc. Ad perpetuam rei memoriam pia matris Ecclesie». Item, altre rescrit qui comença, «Johanes etc. Dilecto suo filio abbati monasterii Sanctarum Crucum». Ítem, altre rescrit qui és tramès al maestre e al covent de Calatrava inductiu que donen al dit monestir los bens que han en Aragó qui comença «Johannes, etc. Dilectis filiis magistro et ffratribus ordinis Calatravensis. Dum ordinis». Item, altre rescrit en qual papa mana al maestre de Calatrava que trameta X frares al dit monestir, qui comença «Johannes, etc. Dilecto filio magistro ordinis Calatrave. Inter cetera", Ítem, li foren liurats lo rescrit del papa tramès al bisbe de Valença sobre la citació del maestre. Ítem, translat en paper de la citació del bisbe e de la resposta feta per lo maestre.

Dels quals rescrits usen los abats en çò que vist serà a ells e an Guillem Jaffer o an $P$. de Celma e no en als e tornen-los a $n$ Bernat d'Averçò (autre main) Redeuntes dicti abbates restituerunt dicta rescripta» (ACA, C., reg. 338, fol. 23r-v)]. Autre exemple de notes de chancellerie en catalan, ibid., fol. $5 \mathrm{r}, 6 \mathrm{r}, 7 \mathrm{v}$.
} 
secretum est à chaque fois précédée d'une note brève qui indique les conditions dans lesquelles il doit en faire usage ${ }^{134}$. Ce cas demeure néanmoins assez isolé au sein des registre ${ }^{135}$, car le contrôle exercé par le pouvoir royal sur les usages de la documentation diplomatique en cours de mission repose essentiellement sur les instructions remises ou formulées aux ambassadeurs, ainsi que sur les missives qui peuvent leur être envoyées une fois qu'ils sont partis.

Les Registra secreta abritent en fait surtout les traces du contrôle effectué sur les documents diplomatiques lorsque la scribania du roi les réceptionne, comme en témoignent les très nombreuses notes de chancellerie rédigées à cette occasion ${ }^{136}$. Une distinction doit ici être faite entre les documents reçus qui n'ont pas été expédiés par la chancellerie aragonaise et ceux qui, déjà enregistrés dans les Registra secreta, sont ramenés par les ambassadeurs à leur retour de mission. La première catégorie comprend tout d'abord des documents remis par des représentants étrangers venus rendre visite au roi d'Aragon. Sans se soucier des modes de réception des ambassadeurs, les notes de chancellerie attestent brièvement de la forme matérielle des lettres de créance, des litterae de statu ou plus rarement des instructions présentées à Jacques II avant d'en effectuer une copie ou un régeste dans les

\footnotetext{
${ }^{134} \mathrm{La}$ note de chancellerie «Si secundus procedat tractatus, dictus nuncius debet alloqui cum rege Ffrancorum circa ipsum negocium pro aliquibus obtinendis ab eo, videlicet de homagio de servicio de veniendo ad curias ipsius regis Ffrancie ratione hereditatis dicte puelle Beatricis filie dicti Johannis, ut possint per procuratorem dicti domini infantis hec explicari. Et proptera fuit tradita ipsi nuncio littera credencie ad dictum Ffrancie regem tenoris sequentis» (ACA, C., reg. 339 , fol. $354 \mathrm{v}$ ) précède la lettre de créance remise par Jacques II à son ambassadeur; une note précise ensuite les conditions d'usage d'une lettre de créance ensuite enregistrée "Circa primum tractatum, si secundus non procedetur» (ibid., fol. 355r), et une autre note stipule quand utiliser un pouvoir remis à l'ambassadeur: «Procuratorium circa primum tractatum, si secundus non procederet» (suivi du pouvoir sous le titre «Super alio tractatu matrimonii ffilie comitis Sabaudie», ibid., fol. 356v).

${ }^{135} \mathrm{La}$ remise au début du mois d'octobre 1302 à l'ambassadeur Jaume Busquet d'un traité de paix avec l'émir de Grenade est elle aussi précédée d'une note où les conditions d'utilisation du document sont brièvement rappelées: «Certum est, quod carta hic registrata, qua sequitur, fuit tradita Jacobo Boscheti predicto, sigillata sigillo maiori tradenda regi Granate, si ei pax et amor regis Aragonie placuerit, et alia debet consimile reportare ab ipso rege Granate ad dominum regem Aragonie juxta formam capitulorum infrascriptorum, cuius carte tenor sequitur" (ACA, C., reg. 334 , fol. $85 \mathrm{v}$ ).

${ }^{136} \mathrm{La}$ scribania du roi ne doit pas être entendue ici comme un lieu fixe, mais bien plutôt comme l'ensemble des escribanos qui accompagnent parfois le roi lors de ses déplacements dans les grandes résidences royales. Des notes de chancellerie mentionnent ainsi que la scribania du roi se trouve à Barcelone (ACA, C., reg. 339, fol. 386r), à Lérida (ACA, C., reg. 336, fol. 7v, fol. $12 \mathrm{r}$ par exemple), à Calatayud (ACA, C., reg. 335, fol. $247 \mathrm{v}(2)$ ) ou à Valence (ACA, C., reg. 334 , fol. $88 v(2))$.
} 
Registra secreta ${ }^{137}$. Des indications similaires sont fournies pour les documents étrangers ramenés par les représentants du roi d'Aragon au retour de leur mission ${ }^{138}$. Dans ce cas, les écrits destinés au roi d'Aragon ne sont cependant pas les seuls à susciter la rédaction de notes de chancellerie au sein des Registra secreta. Au début de l'année 1325, l'infant Pedro arrive de la curie avignonnaise où il avait été envoyé comme ambassadeur, une note de chancellerie accompagnée de brefs régestes indique alors que le fils de Jacques II rapporte des lettres du pape, certaines à l'adresse du roi, mais d'autres dirigées à de hauts dignitaires religieux de la couronne d'Aragon ${ }^{139}$ : les notes du registre témoignent ici du travail de vérification effectué à la chancellerie sur l'ensemble des documents étrangers ramenés par 1'ambassadeur ${ }^{140}$.

${ }^{137}$ Par exemple, ACA, C., reg. 336, fol. 125r; ACA, C., reg. 337, fol. 289v.

${ }^{138}$ Il peut s'agir de lettres, de traités, de lettres de créance ou même de pouvoirs si l'ambassadeur a été renvoyé ad invicem. Guerau de Rocabertí ramène ainsi en juin 1316 des instructions remises par le roi de Majorque: «Idem etiam Geraldus de Rocabertino restituit quamdam cedulam papiream continentem informationem sequentem datam ex parte illustris regis Maioricarum» (ACA, C., reg. 337, fol. 252r (4)). Ce type de notice n'est pas propre aux seuls Registra secreta. Par exemple, Jiménez de Tovia, de retour d'une mission au Portugal et en Castille, rapporte pour sa part - entre autres - une lettre close d'Alphonse XI de Castille: «Item prefatus Eximinus de Tovia attulit quamdam litteram clausam illustris Alfonsi regis Castelle, clausam et intitulatam "domino regi nostro", quo mandante fuit aperta et sibi lecta et est eius continentia sequens» (ACA, C., reg. 1521, fol. 80r).

${ }^{139}$ «Reveniente predicto domino infante Pedro de legatione predicta, attulit octo rescripta papalia, duo ad archiepiscopum Terrachonie et suffragantes eius et ad prelatos et clericos provincie Terrachonie, et alia duo consimilia ad archiepiscopum Cesarauguste et suffragantes eius et ad prelatos et clericos provincie Cesarauguste super concessa decima per dominum papam domino regi ad biennium incipiendum in festo nativitatis beati Johannis Babtiste primo venturo, anno Domini in instantis M CCC XX Quinti.

Aliud clausum super obligatione facta domino regi de remissione ad $\mathrm{X}$ annos, quolibet de mille marchis census et de medietate servicii militaris que fieri debent pro regno Sardinie.

Item aliud comendationis pro domino infante Petro, et rogat in eo pro negocio Maioricarum. Item aliud in quo significat concessionem predicte decime et ut ipsam acceptando dominus rex nulla alia onerosa subsidia inponat ecclesiis.

Item aliud responsivum super facto episcopi Vicense ratione visitationum» (ACA, C., reg. 338 , fol. $155 \mathrm{r}$ ).

${ }^{140}$ Le courrier destiné à des proches conseillers du roi est pour sa part susceptible d'être ouvert, comme en témoigne un extrait d'une lettre adressée par Jacques II à son conseiller Bernat de Sarrià, auparavant ambassadeur auprès de Frédéric III de Sicile: «Jacobus, etc. Nobili et dilecto nostro Bernardo de Serriano, etc. Significamus vobis nos noviter litteras recepisse ab illustri principe Ffrederico Trinaclie rege, karissimo fratre nostro, inter quas erat quadam littera, quam dirigit vobis, quam nos aperuimus et legi fecimus ac intelleximus pro informatione nostra, si aliqua continerent ibi pro nostro facto vel suo, sicquod eam vobis transmittimus presentibus interclusam [...]» (ACA, C., reg. 338, fol. 114v (2)). 
Il existe aussi à l'intérieur des Registra secreta des annotations qui certifient la restitution à la scribania royale de documents expédiés par la chancellerie du roi d'Aragon, en particulier de copies d'originaux (translata), de quelques lettres de créance ou d'instructions à des ambassadeurs ${ }^{141}$. Comme une partie importante de la documentation expédiée et confiée aux envoyés du roi est remise aux destinataires et ne peut donc réintégrer la scribania royale ${ }^{142}$, les mentions de retour simple de documents utilisés demeurent néanmoins assez rares ${ }^{143}$. En revanche, les annotations des scribes font régulièrement état de la restitution $e t$ de la destruction à la chancellerie de documents émis au nom du roi et qui n'ont pu être utilisés. Dans le premier registre de la série (1292-1300), ce sont des notes marginales apposées postérieurement auprès d'une entrée du registre qui se chargent de cette tâche ${ }^{144}$. Elles cèdent progressivement la place à des notes consignées au pied du document, qui signifient que celui-ci a été laniatum, laceratum, ruptum,

\footnotetext{
${ }^{141}$ Gonzalo García, conseiller du roi, de retour d'une mission non accomplie auprès du comte d'Empuries, remet ainsi à Bernat d'Aversó quatre lettres de créance qu'il avait emportées: "Certum est, quod in Ilerda V idus augusti anno Domini $\mathrm{M}^{\circ} \mathrm{CCC}^{\circ} \mathrm{X}^{\circ}$ Gondiçalbus Garcie restituit in scribania domini regis Bernardo de Aversone has IIII ${ }^{\text {or }}$ litteras sibi traditas una cum predicta littera comiti Impuriarum directa clausas, ut sibi tradite fuerant» (ACA, C., reg. 336, fol. 7v). Pour une réintégration d'instructions («capitula»), cf. ACA, C., reg. 338, fol. 87r (retour d'Ot de Montcada d'une ambassade en France). De plus, lorsqu'un ambassadeur a reçu des instructions sans qu'une copie ait pu en être effectuée dans les Registra secreta avant son départ, comme c'est le cas de Domingo García qui se rend en Castille au mois d'août 1310 («Dixit Gundissalvus Garcie Bernardo de Aversoni, quod dominus rex ordinavit capitula dicte legationis, que scripsit et secum atulit dictus archidiaconus, non retento translato» (ACA, C., reg. 336, fol. $13 \mathrm{r}(2)$ ), une transcription peut être effectuée au retour, comme en atteste une note ultérieure: «[...] Reveniente autem dicto Domenico Garcie de legatione predicta fuerunt habita capitula supradicta ab eo, tenor eorum est hic» (ibid., fol. 13v). Pour un exemple de réintégration de translata à la chancellerie, cf. ACA, C., reg. 338, fol. $23 \mathrm{v}$.

${ }^{142} \mathrm{C}$ 'est en particulier le cas de la majorité des lettres de créance, cf. supra note 65.

${ }^{143}$ Les lettres de sauf-conduit émises par des princes étrangers et remises aux ambassadeurs aragonais à leur départ constituent un cas particulier. Obtenues d'un prince étranger, elles sont ensuite conservées à la chancellerie pour être réutilisées. La mention de la remise à la scribania de Jacques II d'un sauf-conduit du roi de France à l'évêque de Huesca qui doit se rendre pour le compte du rọi aragonais à Avignon en mars 1326 («Ffuit tradita predicto episcopo Oscense littera regis Ffrancie sigillo suo pendenti sigillata de conductu nuncorium domini regis», ACA, C., reg. 339 , fol. 199r) est ainsi complétée à son retour dans le registre par une annotation d'une autre main: "Predicta littera regis Ffrancie fuit postea recuperata in regressu dicti episcopi Oscensis» (ibid.). Autre exemple de récupération de litterae de conductu du roi de France pour des ambassadeurs du roi d'Aragon, ibid., fol. $220 \mathrm{v}$.

${ }^{144}$ Un pouvoir inutilisé par Guerau d'Albalat lors d'une mission au Portugal en septembre 1294 est ainsi annulé par l'annotation marginale: "Cancellatum, quia recuperatum fuit procuratorium, quia nil fuit procuratum» (ACA, C., reg. 252, fol. 103r), le pouvoir suivant est rayé et accompagné d'une note similaire: «Cancellata fuerat, eo quia recuperata fuerunt, quia non habuerunt effectum» (ibid., fol. 103v).
} 
fractum ou funeratum, la chancellerie marquant une préférence assez nette pour la laceratio $^{145}$. Les notes précisent fréquemment le mobile qui conduit à la destruction du document. Celui-ci a pu être corrigé, d'où la nécessaire annulation de la première version ${ }^{146}$, mais les documents diplomatiques emmenés par les ambassadeurs sont surtout détruits parce qu'ils n'ont pas été utilisés avec succès par les représentants du roi, en particulier si l'ambassade n'a pas eu lieu ${ }^{147}$, si l'usage du document s'est avéré inutile ou bien si la mission a finalement échoué ${ }^{148}$.

Dans cette perspective, les documents inutilisés qui peuvent présenter un danger pour la couronne, notamment les blancs, sont systématiquement détruits à la chancellerie après leur restitution par les ambassadeurs. Les notes de chancellerie rédigées à cette occasion gagnent en précision et permettent de suivre l'ensemble du processus de contrôle subi par la documentation diplomatique. Nous prendrons ici l'exemple de blancs confiés à Pere Marc

${ }^{145}$ Lorsque des lettres de créance sont enregistrées sur le mode de la copie circulaire, la restitution et la destruction sont indiquées de manière sommaire auprès des noms des destinataires. Cf. par exemple les mentions «restituta et lacerata» apposées postérieurement auprès des entrées de lettres de créance datées du 17 avril 1320 à Montblanc et remises à Juan López et Guerau de Rocabertí pour une mission auprès du pape (ACA, C., reg. 338, fol. 40r-v).

${ }^{146} \mathrm{Cf}$. note 127.

${ }^{147}$ Un exemple significatif est fourni par une note de chancellerie qui précise l'annulation d'une legatio de Bernat de Fonollar qui devait se rendre auprès du pape et la destruction des documents expédiés: "In Ilerda idus augusti anno Domini $\mathrm{M}^{\circ} \mathrm{CCC}^{\circ}$ decimo, Bernardus de Fonollario predictus, quia non ivit in legatione predicta, ut superius videri potest, restituit in scribania domini regis litteram predictam credencie, qua pro eo dirigebatur domino pape. Item restituit decem litteras [-], quarum dirigebantur cardinalibus et episcopo Albiense camarerio et una vicecancallario et altera Amaneno de Lebreto. Item restituit predicta capitula, que super in scriptis missa fuerant. Item restituit capitulum faciens pro fratre Petro Marsilii. Quae omnia lacerata fuerunt» (ACA, C., reg. 336, fol. 12r).

${ }^{148} \mathrm{Par}$ exemple, pour l'ambassade déjà mentionnée (cf. note 145) de Juan López et Guerau de Rocabertí, une note de chancellerie précise: «Revenientibus predictis nunciis, cum nichil egissent super effectu eorum pro quibus confectum fuit procuratorium proxime scriptum, restituerunt ipsum procuratorium, quod fuit laceratum.

Item restituerunt plures litteras regias ex premissis eis traditis quas non presentaverunt et lacerate fuerunt, ut supra in singulis continetur.

Item restituerunt capitula infrascripta informationis eis tradite, quae lacerate fuerunt, quia negocia in ipsis contenta capitulis non processerunt" (ACA, C., reg. 338, fol. 41r). Les documents destinés à des représentants du roi et qui n'ont pu leur être remis sont aussi concernés par la destruction lors de leur réintégration à la chancellerie, deux lettres adressées à Miguel del Corral alors en France en sont les victimes: «Predicte due littere supra proxime registrate non fuerunt presentate, immo reducte ad scribaniam et laniate, quia cursor cui fuerunt tradite, quicquid accessit usque Tholosam, non invenit predictum archidiaconum, quia remansit in partibus Ffrancie, set alii nuncii venerunt ut patebit infra, sicquod dictus cursor redivit cum predictis litteris, ut fuerat informatus, " (ibid., fol. 104v (4)). 
pour une ambassade auprès du roi de Majorque ${ }^{149}$. Une première note indique la date de la remise des blancs (Barcelone, 14 août 1323), en fournit une description matérielle détaillée - trois parchemins blancs munis du sceau pendant du roi sur lesquels rien n'est écrit- avant de rappeler que Pere Marc doit les utiliser selon les instructions qui lui ont été données ${ }^{150}$. Au retour de l'ambassadeur aragonais, une deuxième note de chancellerie est consignée dans le registre à la suite de la précédente ${ }^{151}$. Le scribe y décrit la restitution et la destruction des blancs à la scribania du roi. Dans la camera maioris du palais royal de Barcelone, l'ambassadeur remet en présence du roi à Bernat d'Aversó les blancs qui n'ont pas été utilisés et sont identifiés d'après la description effectuée dans la première notice; Jacques II ordonne alors leur destruction immédiate. En présence du roi, Bernat d'Aversó déchire par conséquent les blancs et les incise, c'est-à-dire qu'il cisaille le document aux plis en provoquant par le support des coupures en forme de chevron, avant de rompre les sceaux ex toto $^{152}$. La destruction d'un blanc est ici devenue un acte solennel et spectaculaire, et le scribe consigne en fait dans le Registrum secretum une petite cérémonie documentaire effectuée immédiatement au retour de l'ambassadeur afin d'éviter l'utilisation malveillante de ces documents particulièrement dangereux ${ }^{153}$.

${ }^{149}$ Sur les blancs, cf. G. DiCKINSON, Blanks and Blank Charters in the fourteenth and fifteenth Centuries, «English Historical Review», 66 (1951), p. 375-387.

${ }^{150} \ll$ Et est certum quod, ad mandatum expressum domini regis, fuerunt tradita in Barchinone XIX kalendas septembris anno predicto [1323] dicto Petro Marti in scribania domini regis tria instrumenta pergamenea alba, in quibus nichil omnino scriptum erat, set sigillata sigillo domini appendicio ipsius domini regis, ut ipse Petrus Marti juxta comissa sibi in sua legatione uti valeat et scribi facere in eis, prout expedierit et negocia postulabunt» (ACA, C., reg. 339, fol. 386r).

${ }^{151}$ «Postmodum autem, reveniente dicto Petro Marti a dicta legatione in Barchinona II nonas septembris anno predicto, restituit in presencia domini regis in camera maiori sui palacii Barchinone Bernardo de Aversone, notario dicti domini regis, presente Guillelmo Augustini, scriptore ipsius domini regis, predicta eadem tria instrumenta pergamenea alba in quibus nichil scriptum fuerat, set tradita fuerant dicto Petro Marti sigillo communi pendenti dicti domini regis ut predicitur sigillata, sicquod incontinenti coram ipso domino rege et de mandato suo ipsa tria instrumenta fuerunt per dictum Bernardum lacerata et inscisa et sigilla pendentia in eis ex toto confracta» (Ibid.).

${ }^{152}$ Cf. M.M. CÁRCEL ORTí (éd.), Vocabulaire international de la diplomatique, Valence : Generalitat Valenciana. Conselleria de Cultura. Universitat de València (Commission Internationale de Diplomatique), 1994, p. 40. etc.

${ }^{153}$ Autres exemples de destructions de blancs: ACA, C., reg. 335, fol. $283 \mathrm{v}$, fol. $291 \mathrm{v}-292 \mathrm{r}$, 
De même que les efforts fournis pour ordonnancer la documentation diplomatique enregistrée, le souci de contrôler le plus minutieusement possible les destinées de la documentation remise aux ambassadeurs a pour conséquence une mise à jour régulière des Registra secreta grâce aux notes de chancellerie. D'autre part, les très fréquentes destructions de documents témoignent du caractère fondamentalement temporaire d'une bonne partie de la documentation diplomatique enregistrée. De nombreux documents des Registra secreta n'auront ainsi été valables qu'au cours de la brève période comprise entre une première note de chancellerie qui signifie leur remise à un ambassadeur et une seconde annotation des scribes qui atteste de leur destruction. Dès lors, comme certaines lettres closes ont été ramenées puis détruites sans avoir été ouvertes, en l'absence de minutes conservées, le registre peut renfermer le seul témoignage de leur courte existence ${ }^{154}$.

L'examen de la tenue et de l'économie interne des Registra secreta a montré qu'ils constituaient à la fois un laboratoire d'expérimentation pour le rassemblement des documents diplomatiques enregistrés et un outil de travail essentiel pour la chancellerie qui s'efforce de suivre l'utilisation des originaux par les ambassadeurs. Ils participent en ce sens du contrôle exercé par le pouvoir royal sur l'action de ses envoyés à l'étranger, et les multiples annotations apposées par les scribes dans les Registra secreta contribuent avec les lettres de créance, les procurations et les instructions à délimiter la marge de manœuvre dont disposent les ambassadeurs au cours de leur mission. On ne peut donc les définir uniquement comme des «volumes dans lesquels on procède à un enregistrement successif d'actes, de lettres, de comptes» ${ }^{155}$, mais les révisions régulières dont ils portent les traces incitent plutôt à voir en eux des instruments vivants de l'activité de la chancellerie. Garants de l'authenticité des documents diplomatiques qui y sont enregistrés, témoins des différentes modifications qu'ont pu subir des actes à la validité souvent temporaire, les Registra secreta forment à la scribania du roi la mémoire active et sans cesse

\footnotetext{
${ }^{154} \mathrm{Au}$ retour de Ramon de Masquefa (cf. note 135), une note précise ainsi: «in reditu predicti fratris Raimundi restituit hanc litteram clausam quia non presentaverat eam, que fuit lacerata" (ACA, C., reg. 339, fol. 355r).

${ }^{155}$ D'après la définition de M.M. CÁRCEL OrTí (éd.), opus cit. (cf. note 152), p. 38.
} 
réécrite de l'administration d'une partie des affaires diplomatiques aragonaises $^{156}$.

Les autres usages de ces registres procèdent de la même logique. Les Registra secreta abritent ainsi des formulaires de chancellerie qui servent de modèle pour la rédaction des documents diplomatiques par les scribes ${ }^{157}$, ils permettent aussi parfois de repérer par une indication sommaire le lieu de conservation d'un document important ${ }^{158}$. De manière plus générale, ces registres facilitent la préparation de l'action diplomatique polymorphe déployée par le pouvoir royal aragonais. Ils sont dans cette perspective employés comme des archives authentiques, puisque l'on s'y réfère pour rédiger les versions actualisées de documents déjà enregistrés ou pour préparer les dossiers documentaires nécessaires pour les ambassades ${ }^{159}$. Outils de l'ombre et du secret, les Registra secreta peuvent aussi être utilisés de manière plus spectaculaire au cours même des rencontres diplomatiques. En janvier 1318, le roi d'Aragon reçoit des mains de l'ambassadeur Jaspert de Castellnou une lettre close du roi Sanche de Majorque dont le contenu lui paraît inacceptable, car elle met en cause l'action de ses ambassadeurs Bernat Guillem Sa Portella et Joan Borgunyó auprès du roi majorquin. Jacques II

\footnotetext{
${ }^{156} \mathrm{La}$ fonction mémorielle de l'enregistrement apparaît parfois dans la justification de certaines notes des Registra secreta: «Ut memoria habeatur ad hec, solum hic scriptum est, quod predictus Maioricarum rex nunc concessit mutuare domino regi nostro quantitatem duodecim mille librarum Barchinone convertendam in solvendis domini regis et domini infantis Alfonsi stipendiis [...]. Et de hoc fuit confectum instrumentum debitorum registratum in registro solutionum actum in civitate Barchinone $\mathrm{V}$ idus augusti anno predicto et clausum per Guillelmum Augustini scriptorem domini regis et notarium publicum [...]" (ACA, C., reg. 339, fol. 385v (2)).

${ }^{157}$ ACA, C., reg. 336, fol. 0r. Sur les formulaires de chancellerie, cf. Fr. AUTRAND, $L$ 'enfance de l'art diplomatique La rédaction des documents diplomatiques en France XIV'me-XV'é siècles, dans L. BÉLY (dir.), L'invention de la diplomatie Moyen Age Temps Modernes, Paris : PUF, 1998, p. 207-224.

${ }^{158}$ Les annotations des scribes indiquent ainsi parfois que des documents reçus se trouvent «in cancellaria», cf. ACA, C., reg. 334, fol. 88v.

${ }^{159}$ Lorsque Jacques II envoie en mars 1326 au pape Jean XXII ses ambassadeurs Gaston évêque de Huesca et Berenguer de Sant Viçenc, il remet à ces derniers un dossier constitué de sept projets de paix entre Frédéric III de Sicile et Robert d'Anjou, roi de Naples. Selon leurs instructions, les ambassadeurs du roi d'Aragon doivent dire au pape que ces projets de paix ont été vérifiés d'après ses registres: «E per çò, sant pare, que la vostra sanctitat veja e conega que nostre senyor lo rey ha dret e bon enteniment en aquestes affers, desigan molt que venguessen a bona pau e a bona fi e que no roman en ell de cercar totes maneres per què-s pogués fer, tramet vos totes aquelles formes de pau que ell sap que són estades mogudes tro vuy per diverses temps passats entre ls reys damuntdits $e$ axi com les ha pogudes fer trobar en sos registres de lonc de temps a ençà, les quals a la vostra sanctitat som ara aparellats de mostrar o quant vós plàcia. [...]" (ACA, C., reg. 339, fol. 197r, souligné par nous).
} 
ordonne alors de faire reconnaître dans les registra les articles de la legatio qui avait été confiée à ses ambassadeurs, afin de montrer immédiatement au représentant majorquin (ad occulum hostenda) les instructions enregistrées et de répliquer ainsi aux protestations de Sanche. À la demande de Jaspert de Castellnou, une copie des articula est ensuite effectuée pour être remise au roi de Majorque ${ }^{160}$. L'authenticité de la documentation enregistrée dans les Registra secreta permet par conséquent de vérifier la validité d'une information au sein de la chancellerie, mais le secret où sont d'ordinaire confinés les registres fait aussi de leur ostension devant un ambassadeur étranger un argument difficilement réfutable. Lorsque les Registra secreta quittent le secret, c'est encore pour renforcer le pouvoir royal.

${ }^{160}$ Lettre de Jacques II à Sanche de Majorque: «Excellenti principi Sancio, Dei gracia regi Maioricarum, comiti Rossilionis et Ceritanie ac domino Montispesuli, karissimo consanguineo nostro. Jacobus per eandem rex Aragonum, etc. Salutem et felices ad vota successus. Significamus vobis nobilem virum Jaspertum, vicecomitem Castri Novi, ad nos per vos cum littera credencie super quibusdam negociis destinatum presentasse nobis quoddam scriptum clausum vestro sigillo sigillatum, quod misistis nobis super facto nobilium Guillelmi de Caneti et Petri de Fenolleto, quodque nos apperuimus et que eius series continebat audivimus et intelleximus diligenter, de quibus vehementer fuimus admirati, scientes ea qua ad nos veritatem nullatenus continere. Et continuo legationum articulos per nos comissarum nobili Bernardo Guillelmi de Portella et venerabili Johanni Burgundi sacriste Maiorice, quando ipsos ad regem Ffrancie misimus, sicut scitis, in registro nostro fecimus recognosci, et etiam dicto Jasperto ad occulum hostenda, et ad instanciam etiam predicti Jasperti mittimus vobis copiam legationis, quam non soli dicto sacriste, set etiam ambobus predictis nobili Bernardo Guillelmi et sacriste comisimus, prout plenius in cedula hic interclusa videbitis contineri. Nichilominus etiam vocavimus ad nos dictum sacristam presentem in curia nostra, cui hostendimus et perlegi fecimus dictum scriptum, qui miratus quamplurimum et turbatus se de contentis in ipso scripto totaliter excusavit, dicens se processisse et fecisse una cum dicto nobili tam in predictis, quam aliis secundum informationem nostram et non alias et per se solum processisse in nullo quia hoc informatio non dicebat, affectantes insuper rem prodire in lucem ad nos dictum nobilem Bernardum Guillelmi providimus evocandum. Datum Valencie VIII idus januarii anno Domini $\mathrm{M}^{\circ} \mathrm{CCC}^{\circ} \mathrm{XVII}^{\circ}$.

Bernardus de Aversone, mandato regis et fuit eidem lecta.

Et est certum, quod in predicta littera fuit missa interclusa dicto regi Maioricarum copia familiaris legationis, de qua in ipsa littera dicitur. Qua legatio familiaris supra registrata est, et inde fuit sumpta ex legatione qua comissa fuit dictis Bernardo Guillelmi et sacriste et in premissa cedula fuit scripta ab eo loco quo incipit:

«Sequitur legatio familiaris» et subsequenter usque ad litteram credencie inclusive» (ACA, C., reg. 337 , fol. $264 \mathrm{r}(1)$, souligné par nous). Les instructions de la «legatio familiaris» mentionnée sont enregistrées quelques folios auparavant (ibid., fol. 247v-248r). 